\title{
Interfacial insights into 3D plasmonic multijunction nanoarchitecture toward efficient photocatalytic performance
}

\section{Kemeng Ji}

Beijing Key Laboratory for Green Catalysis and Separation, Key Laboratory of Beijing on Regional Air Pollution Control, Key Laboratory of Advanced Functional Materials, Education Ministry of China, and Laboratory of Catalysis Chemistry and Nanoscience, Department of Chemistry and Chemical Engineering, College of Environmental and Energy Engineering, Beijing University of Technology, Beijing 100124, PR China.

WPI Advanced Institute for Materials Research, Tohoku University, Sendai 980-8577, Japan.

Email: jkm728@gmail.com

\section{Hamidreza Arandiyan}

Particles and Catalysis Research Group, School of Chemical Engineering, The University of New South Wales, Sydney NSW 2052, Australia.

Email: h.arandiyan@unsw.edu.au

\section{Pan Liu}

WPI Advanced Institute for Materials Research, Tohoku University, Sendai 980-8577, Japan. Email: liu.pan.b8@wpi-aimr.tohoku.ac.jp

\section{Ling Zhang}

School of Optical-Electrical and Computer Engineering, University of Shanghai Science and Technology, Shanghai 200093, PR China.

Email: zhang.luna@hotmail.com

\section{Jiuhui Han}

WPI Advanced Institute for Materials Research, Tohoku University, Sendai 980-8577, Japan. 
Email: hanjh08@gmail.com

\section{Yacong Xue}

School of Engineering, Tohoku University, Sendai 980-8579, Japan.

Email: xueyacong@yahoo.co.jp

\section{Jungang Hou}

State Key Laboratory of Fine Chemicals, Institute of Artificial Photosynthesis, Dalian University of Technology, Dalian 116024, PR China.

E-mail: jhou@dlut.edu.cn

\section{Hongxing Dai}

Beijing Key Laboratory for Green Catalysis and Separation, Key Laboratory of Beijing on Regional Air Pollution Control, Key Laboratory of Advanced Functional Materials, Education Ministry of China, and Laboratory of Catalysis Chemistry and Nanoscience, Department of Chemistry and Chemical Engineering, College of Environmental and Energy Engineering, Beijing University of Technology, Beijing 100124, PR China.

Email: hxdai@bjut.edu.cn

Corresponding author: Kemeng Ji, Email: jkm728@gmail.com; Jungang Hou, Email: jhou@ dlut.edu.cn; Hongxing Dai, Email: hxdai@bjut.edu.cn 


\section{Interfacial insights into 3D plasmonic multijunction nanoarchitecture toward efficient photocatalytic performance}

Kemeng Ji ${ }^{\mathrm{a}, \mathrm{b}, *}$, Hamidreza Arandiyan ${ }^{\mathrm{c}}$, Pan Liu ${ }^{\mathrm{b}}$, Ling Zhang ${ }^{\mathrm{d}}$, Jiuhui Han ${ }^{\mathrm{b}}$, Yacong Xue ${ }^{\mathrm{e}}$, Jungang $\mathrm{Hou}^{\mathrm{f}, *}$, and Hongxing Dai ${ }^{\mathrm{a}, *}$

${ }^{a}$ Beijing Key Laboratory for Green Catalysis and Separation, Key Laboratory of Beijing on Regional Air Pollution Control, Key Laboratory of Advanced Functional Materials, Education Ministry of China, and Laboratory of Catalysis Chemistry and Nanoscience, Department of Chemistry and Chemical Engineering, College of Environmental and Energy Engineering, Beijing University of Technology, Beijing 100124, PR China.

${ }^{\mathbf{b}}$ WPI Advanced Institute for Materials Research (AIMR), Tohoku University, Sendai 9808577, Japan.

${ }^{\mathbf{c}}$ Particles and Catalysis Research Group, School of Chemical Engineering, The University of New South Wales, Sydney NSW 2052, Australia.

${ }^{\mathrm{d}}$ School of Optical-Electrical and Computer Engineering, University of Shanghai Science and Technology, Shanghai 200093, PR China.

${ }^{\mathbf{e}}$ School of Engineering, Tohoku University, Sendai 980-8579, Japan.

${ }^{\mathbf{f}}$ State Key Laboratory of Fine Chemicals, Institute of Artificial Photosynthesis, Dalian University of Technology, Dalian 116024, PR China.

*Corresponding author: Kemeng Ji, Email: jkm728@gmail.com; Jungang Hou, Email: jhou@ dlut.edu.cn; Hongxing Dai, Email: hxdai@bjut.edu.cn 


\section{Abstract}

Through effectively harvesting and converting solar energy, photocatalysis has become one of the most important technologies in wastewater decontamination and hydrogen production. Currently, extensive studies are being conducted to develop photocatalysts with advanced features, such as visible-light response, heterogeneous nanoarchitecture, plasmonic effect, and excellent optical behavior. Finding efficient utilization technique to improve photocatalytic performance motivates researchers all over the world. Herein, we demonstrate the design of a visible-light-driven $\mathrm{Pd} / \mathrm{Fe}_{2} \mathrm{O}_{3} / \mathrm{BiVO}_{4}$ hybrid with 3D ordered macro-/mesoporous (3DOM) nanoarchitecture for efficiently photocatalytic organic degradation and photoelectrochemical (PEC) water splitting. The hybrid photocatalyst exhibited two-tier bandgap energies and possessed enhanced ability to harvest visible light and separate photo-induced carriers. It is shown that, over the $\mathrm{Pd} / \mathrm{Fe}_{2} \mathrm{O}_{3} / 3 \mathrm{DOM}-\mathrm{BiVO}_{4}$ photocatalyst, not only the refractory phenol could be rapidly degraded into $\mathrm{CO}_{2}$ and $\mathrm{H}_{2} \mathrm{O}$, but also the photoconversion efficiency was greatly improved in water splitting to generate $\mathrm{H}_{2}$. The excellent photocatalytic performance of $\mathrm{Pd} / \mathrm{Fe}_{2} \mathrm{O}_{3} / \mathrm{BiVO}_{4}$ was associated with the construction of low-crystalline plasmonic heterointerfaces through the 3DOM framework. The produced synergistic action enabled the hybrid material to absorb the sunlight adequately and transfer the photoexcited carriers expediently to drive phenol degradation or hydrogen evolution from water.

\section{Keywords}

Three-dimensionally ordered macropore; Bismuth vanadate; Supported heterojunction photocatalyst; Phenol degradation; Water splitting 


\section{Introduction}

Due to the depletion of fossil fuel resources and serious environmental pollution, it is a worldwide priority target to utilize the abundant and economical solar energy to drive chemical reactions (e.g., wastewater decontamination and water splitting for hydrogen production) [1-3]. Sunlight-driven photocatalysis emerges to be one of the most conspicuous technologies to alleviate the above encountered problems. However, the effectiveness of a photocatalytic process is greatly influenced by the capability of a photocatalyst to harvest sunlight (in particular, ca. $44 \%$ visible light) and suppress the rapid re-combination of photogenerated charge carriers (i.e., electron-hole pairs) [3]. Despite tremendous efforts on this topic have been made, it is not easy to obtain a high-performance photocatalyst with one single component or a simple structure due to the complexity of the involved photocatalytic processes.

To fully utilize solar energy, semiconductors with high bandgap energies should be avoided firstly in view of their limited light absorption. For instance, the pure $n$-type $\mathrm{TiO}_{2}$ (with its bandgap energy $\left(E_{\mathrm{g}}\right)$ at $\left.\sim 3.2 \mathrm{eV}\right)$ can only respond to the UV light $(\sim 5 \%$ of the whole solar spectrum) [4]. Extensive research has currently been devoted to the development of visible-lightdriven catalysts with narrower bandgap energies. Since Kudo and coauthors firstly reported the photocatalysis of $\mathrm{BiVO}_{4}\left(n\right.$-type, $\left.E_{\mathrm{g}} \approx 2.4 \mathrm{eV}\right)$ in 1998 [5], $\mathrm{BiVO}_{4}$ has been one of the most frequently used materials for water purification and splitting due to its activity, chemical neutrality and stability, historical non-toxicity (e.g., the wide application as bright yellow pigment [6]), and environmental benign [7-9]. The $n$-type hematite $\left(\alpha-\mathrm{Fe}_{2} \mathrm{O}_{3}, E_{\mathrm{g}} \approx 2.0 \mathrm{eV}\right)$ is another superior photocatalyst of particular interest because of its low cost, environmental friendliness, easy preparation, and high thermodynamic stability [10-12]. However, the activity of this semiconductor is relatively poor due to its low carrier mobility, short minority-carrier lifetime (ca. 10 ps) and diffusion length (ca. 2-4 nm) [12]. Besides, $\mathrm{Fe}_{2} \mathrm{O}_{3}$ exhibits a good stability in a wide 
range of $\mathrm{pH}$ values, and thus an external bias is generally required when it serves to initiate $\mathrm{H}_{2}$ evolution $[13,14]$. In addition to the choice of catalytic components, either the composition or the architecture should be considered for an ideal photocatalyst. To address the inherent problems of simple semiconductor photocatalysts, multifunctional semiconductor photocatalysts with heterogeneous or plasmonic metallic nanostructures have been generated recently, showing a promise for practical photocatalytic applications $[4,15]$. The co-catalyst components (e.g., various $n$ - or $p$-type metal oxides like $\mathrm{Fe}_{2} \mathrm{O}_{3}[12,16]$ and noble metals like $\mathrm{Au}, \mathrm{Ag}, \mathrm{Pt}$, and $\left.\mathrm{Pd}[17,18]\right)$ not only can provide active sites with lower activation barriers for photochemical transformations, but also will enhance the separation rates of electron-hole pairs by building intense and spatially non-homogeneous oscillating electric fields or the Schottky barriers at the interface [4,17]. It has been reported that when two ingredients are separated by $\sim 1 \mathrm{~nm}$, the most intensive electric field can be achieved [4]. High-efficiency separation of photoexcited electron-hole pairs has also been realized in the ternary nanojunction systems, such as $\mathrm{Au}-\mathrm{Pd} / \mathrm{TiO}_{2}$ [18], $\mathrm{CdS}-\mathrm{Au}-\mathrm{TiO}_{2}$ [19], $\mathrm{Fe}_{2} \mathrm{O}_{3} /$ graphene/BiV ${ }_{1-x} \mathrm{Mo}_{x} \mathrm{O}_{4}$ [20], and $\mathrm{Pt} / \mathrm{MO}_{x} / \mathrm{BiVO}_{4}(\mathrm{M}=\mathrm{Co}, \mathrm{Mn})$ [17]. Particularly, plasmonic metallic nanostructures are beneficial for concentrating the plasmon-excited hot electrons to drive photocatalysis, and also they can directly act as the light absorber and the catalytically active sites [4,21-23]. Furthermore, according to the plasmonic mechanisms, the optical property and geometric arrangement can have a positive role in enhancing the surface plasmon resonance effect (e.g., the realization of multipolar plasmon modes on uniform and length-variable Ag nanorods [24]) and the photocatalytic activity (e.g., the dramatic enhancement in photocatalytic activity of methyl orange degradation over $\mathrm{Au} / \mathrm{CeO}_{2}$ plasmonic nanorods [25] and tetracycline decomposition over $\mathrm{Ag} / \mathrm{Bi}_{3} \mathrm{TaO}_{7}$ plasmonic nanocomposite [26]) of a welldesigned composite system [4]. Thus, hybridizing desirable materials with unique optical configuration (e.g., the three-dimensional structure [27]) is doubtlessly an effective strategy to 
fully utilize the plasmonic behavior and heterostructures. Recently, many efforts have been made on the use of the colloidal crystal templates (e.g., polystyrene, polymethyl methacrylate (PMMA) or $\mathrm{SiO}_{2}$ microspheres) methods to generate the three-dimensionally ordered macroporous (3DOM) materials (e.g., doped or undoped $\mathrm{TiO}_{2}[23,28]$ and $\mathrm{MVO}_{4}(\mathrm{M}=\mathrm{Bi}$, In) [29-31]) for various applications such as photonic crystals, optical sensors, photoelectrochemical (PEC) catalysts, capacitors, dye-sensitized solar cells, battery materials, and fuel cells [32,33]. These materials usually possess attractive features, such as relatively high surface areas, large voidage (ca. 74\%), interconnected macropores with thin shells, and unique photonic behaviors originating from the periodic macro-/mesoscopic voids $[2,23,33,34]$. To the best of our knowledge, no comprehensive model has been developed so far to clarify the interplay of different factors that affect the overall performance and to guide the design for high-efficient photocatalytic materials [4].

Inspired by these viewpoints, taking into account the cost-effective $\mathrm{BiVO}_{4}$ and $\mathrm{Fe}_{2} \mathrm{O}_{3}$ together with a trace amount of $\mathrm{Pd}$ (only $0.2 \mathrm{wt} \%$ ), we herein propose an innovative design to formulate the nanoarchitectured photocatalyst (Figure 1): plasmonic $\mathrm{Pd}$ sub-nanocluster/amorphous $\mathrm{Fe}_{2} \mathrm{O}_{3}$ nanofilm/3DOM $\mathrm{BiVO}_{4}$ with low-crystalline surface. In addition to the intrinsic activity of each component as described above, further benefited by the heterogeneous structure, stepped phragmoid surface, and plasmonic metallic nanostructure on 3DOM entity, the as-obtained $\mathrm{Pd} / \mathrm{Fe}_{2} \mathrm{O}_{3} / 3 \mathrm{DOM} \mathrm{BiVO}_{4}$ composite can effectively harvest the visible light and convert the photons into electron-hole carriers for the subsequent chemical transformations. Using the Fenton-type degradation of stubborn phenol as model reaction, the engineered nanojunction photocatalyst achieved high-efficiency elimination of phenol under visible light irradiation. Meanwhile, compared to its counterparts, much larger photocurrent density and photoconversion efficiency for PEC water splitting were observed over this hybrid photocatalyst as a photoanode. 
The role of each component in the composite was identified according to the characterization results.

\section{Experimental}

\subsection{Photocatalyst synthesis}

\subsubsection{Powder samples for photocatalytic phenol degradation}

Monoclinic 3DOM $\mathrm{BiVO}_{4}$ (denoted as 3D-BiV) was first fabricated by a PMMA-templating strategy. $3.0 \mathrm{~g} f c c$-packed PMMA template (ca. $300 \mathrm{~nm}$ in diameter) was soaked in a mixture of precursor solution $\left(10 \mathrm{mmol}\right.$ of $\mathrm{Bi}\left(\mathrm{NO}_{3}\right)_{3} \cdot 5 \mathrm{H}_{2} \mathrm{O}, 10 \mathrm{mmol}$ of $\mathrm{NH}_{4} \mathrm{VO}_{3}, 10 \mathrm{mmol}$ of ascorbic acid, $3.0 \mathrm{~mL}$ of glycol, $6.0 \mathrm{~mL}$ of methanol, $1.0 \mathrm{~mL}$ of $\mathrm{HNO}_{3}(68 \mathrm{wt} \%)$, and $6.0 \mathrm{~mL}$ of deionized water) for $3 \mathrm{~h}$. After filtration and drying in air at room temperature (RT), the PMMA solid was first calcined in $\mathrm{N}_{2}(100 \mathrm{~mL} / \mathrm{min})$ at a ramp of $1{ }^{\circ} \mathrm{C} / \mathrm{min}$ from RT to $300{ }^{\circ} \mathrm{C}$ and kept at $300{ }^{\circ} \mathrm{C}$ for $2 \mathrm{~h}$; After being cooled to RT, the as-obtained solid was further calcined in air (100 $\mathrm{mL} / \mathrm{min})$ from RT to $400{ }^{\circ} \mathrm{C}$ and maintained at this temperature for $2 \mathrm{~h}$. Then, the $4 \mathrm{wt} \% \mathrm{Fe}_{2} \mathrm{O}_{3} / 3 \mathrm{DOM} \mathrm{BiVO}_{4}$ (denoted as $4 \mathrm{Fe} / 3 \mathrm{D}-\mathrm{BiV}$ ) photocatalyst was prepared using the incipient-wetness impregnation method. The typical procedure is as follows: (1) the as-prepared 3D-BiV was first immersed in the precursor solution containing a certain amount of $\mathrm{Fe}\left(\mathrm{NO}_{3}\right)_{3} \cdot 9 \mathrm{H}_{2} \mathrm{O}$ and isopropanol; (2) after being dried at $80{ }^{\circ} \mathrm{C}$ for $12 \mathrm{~h}$, the solid was annealed at $140{ }^{\circ} \mathrm{C}$ for $8 \mathrm{~h}$ and then at $200{ }^{\circ} \mathrm{C}$ for $2 \mathrm{~h}$ to obtain the $4 \mathrm{Fe} / 3 \mathrm{D}-\mathrm{BiV}$ sample. The $0.2 \mathrm{wt} \% \mathrm{Pd} / 4 \mathrm{wt} \% \mathrm{Fe}_{2} \mathrm{O}_{3} / 3 \mathrm{DOM} \mathrm{BiVO}_{4}$ (denoted as 0.2Pd/4Fe/3D-BiV) sample was prepared via a bubbling-assisted sol deposition-adsorption route using the $4 \mathrm{Fe} / 3 \mathrm{D}-\mathrm{BiV}$ as support and the $\mathrm{Pd}$ sol $(2 \mathrm{mmol} / \mathrm{L})$ in the ice-water bath under vigorous bubbling for $10 \mathrm{~h}$. The $\mathrm{Pd}$ sol was obtained by reducing the aqueous solution of $\mathrm{PdCl}_{2}$ and polyvinyl alcohol (PVA, MW = 10,000 g/mol; Pd/PVA mass ratio = $1.5: 1$ ) with $0.05 \mathrm{~mol} / \mathrm{L}$ $\mathrm{NaBH}_{4}$ aqueous solution $\left(\mathrm{Pd} / \mathrm{NaBH}_{4}\right.$ molar ratio = $\left.1: 5\right)$. At last, the $0.2 \mathrm{Pd} / 4 \mathrm{Fe} / 3 \mathrm{D}-\mathrm{BiV}$ sample 
was collected after filtration, drying at $200{ }^{\circ} \mathrm{C}$ for $2 \mathrm{~h}$, washing with deionized water and alcohol, and drying at $70{ }^{\circ} \mathrm{C}$ for $12 \mathrm{~h}$. For reference, the $0.2 \mathrm{Au} / 4 \mathrm{Fe} / 3 \mathrm{D}-\mathrm{BiV}$ and $0.2 \mathrm{Pt} / 4 \mathrm{Fe} / 3 \mathrm{D}-\mathrm{BiV}$ samples were obtained via the above route using $\mathrm{HAuCl}_{4}$ and $\mathrm{H}_{2} \mathrm{PtCl}_{6}$ as $\mathrm{Au}$ and $\mathrm{Pt}$ sources, respectively. Before characterization and photocatalytic degradation evaluation, the photocatalysts were further pretreated at $200{ }^{\circ} \mathrm{C}$ for $2 \mathrm{~h}$, after which they were washed with ethanol and water and dried at $70{ }^{\circ} \mathrm{C}$ for $12 \mathrm{~h}$.

\subsubsection{Photoanodes for the semi-quantitative PEC water splitting}

The same chemicals were used to prepare the photoanodes on an indium-tin-oxide (ITO) conducting glass. Using the as-prepared PMMA emulsion, the hard template was deposited on the ITO glass via the evaporation self-assembly route. All of the other steps were similar to those for the preparation of the above powder samples, except that dripping a certain amount of the precursor solution or sol on the PMMA surface to obtain the $3 \mathrm{D}-\mathrm{BiV}, \mathrm{Fe}_{2} \mathrm{O}_{3} / 3 \mathrm{D}-\mathrm{BiV}$, and $\mathrm{Pd} / \mathrm{Fe}_{2} \mathrm{O}_{3} / 3 \mathrm{D}-\mathrm{BiV}$ photoanodes on the ITO glass.

\subsection{Photocatalyst characterization}

The as-prepared samples were characterized by means of numerous techniques. X-ray powder diffraction (XRD) patterns of the samples were collected on a Bruker D8 Advance diffractometer equipped with $\mathrm{Cu} K \alpha$ radiation and $\mathrm{Ni}$ filter $(\lambda=0.15406 \mathrm{~nm})$. The operating voltage and current were $40 \mathrm{kV}$ and $35 \mathrm{~mA}$, respectively. Laser Raman spectra of the samples were acquired using a Renishaw inVia Raman apparatus with an excitation laser wavelength of $785 \mathrm{~nm}$. Fourier transform infrared (FT-IR) spectra of the samples were recorded in the $400-4000 \mathrm{~cm}^{-1}$ range on a Bruker Vertex 70 spectrometer, taking $\mathrm{KBr}$ as the dispersion medium. Elemental analysis was carried out on an inductively coupled plasma atomic emission spectroscopic (ICP-AES, Thermo Electron IRIS Intrepid ER/S) apparatus. Scanning electron microscopic (SEM) images of the samples were collected on a Gemini Zeiss Supra 55 apparatus (operating voltage $=5 \mathrm{kV}$ ). 
Transmission electron microscopic (TEM) images and selected-area electron diffraction (SAED) patterns of the samples were recorded on a JEOL-2010 equipment operated at $200 \mathrm{kV}$. Also, scanning transmission electron microscopic (STEM) images of the samples was obtained on an aberration-corrected JEOL $2100 \mathrm{~F}$ at $200 \mathrm{keV}$ accelerating voltage with an ED X-ray detector. The device is equipped with a hot field-emission electron source and is capable of third-order aberration correction. High-resolution electron energy-loss spectroscopic (EELS) spectra of the samples were collected using a Gatan Enfina spectrometer, and energy dispersion was $0.5 \mathrm{eV}$ per pixel. Surface areas and pore-size distributions of the samples were obtained using the BrunauerEmmett-Teller (BET) and Barrett-Joyner-Halenda $(\mathrm{BJH})$ methods according to the nitrogen adsorption-desorption isotherms measured at $-196{ }^{\circ} \mathrm{C}$ on a Micromeritics ASAP 2020 analyzer, in which the samples were degassed at $200{ }^{\circ} \mathrm{C}$ for $2 \mathrm{~h}$. X-ray photoelectron spectroscopic (XPS) technique was used to determine the metal oxidation states and surface element compositions of the samples on a Thermo Scientific K-Alpha, with the excitation source and resolution being Al $K \alpha(1486.67 \mathrm{eV})$ and $0.1 \mathrm{eV}$, respectively. The samples were directly measured without being pretreated in $\mathrm{O}_{2}$ or at a high temperature. Binding energies (BEs) of the elements were calibrated against the $\mathrm{C} 1 \mathrm{~s}$ signal at $\mathrm{BE}=284.6 \mathrm{eV}$. The ultraviolet-visible (UV-Vis) diffuse absorbance and reflectance spectra of the samples in the range of 200-900 nm were determined on a Shimadzu UV-2450 spectrophotometer using $\mathrm{BaSO}_{4}$ as the standard. The photoluminescence (PL) spectra of the samples were measured using a Renishaw Raman microscope (Renishaw InVia RM 1000) with the incident laser wavelength of $514.5 \mathrm{~nm}$. The laser power was set at $0.2 \mathrm{~mW}$.

\subsection{Photocatalytic evaluation}

The phenol degradation (with an initial concentration $\left(C_{0}\right)$ of $0.4 \mathrm{mmol} / \mathrm{L}$ ) over the photocatalysts and Degussa P25 $\left(\mathrm{TiO}_{2}\right)$ (referring to our previous work [30]) was conducted in a quartz reactor (QO250, Beijing Changtuo Sci. \& Technol. Co., Ltd.) under visible light 
irradiation (with a 400-nm cutoff filter) using a 300-W Xe lamp (PLS-SXE300, Tianjin Dongli Teaching Instrument Factory). The reactant solution was kept at RT by the flowing cool water and bubbled with air all the time. Prior to irradiation, the suspension (with $0.1 \mathrm{~g}$ of the sample in $100 \mathrm{~mL}$ of the phenol solution in the presence of $0.6 \mathrm{~mL}$ of $30 \mathrm{wt} \% \mathrm{H}_{2} \mathrm{O}_{2}$ ) was ultrasonicated for $0.5 \mathrm{~h}$ and then magnetically stirred in the dark for $2 \mathrm{~h}$. During the irradiation, $5 \mathrm{~mL}$ of the suspension was sampled at given time intervals and centrifuged to remove the solid photocatalyst. The absorption spectra of all of the sampled solutions were recorded on UV-vis spectrophotometer, and some typical liquid samples were chosen to be analyzed by the electrospray ionization mass spectrometry (ESI-MS).

The PEC properties were measured in a three-electrode cell using the 3D-BiV, Fe/3D-BiV, and $\mathrm{Pd} / \mathrm{Fe} / 3 \mathrm{D}-\mathrm{BiV}$ heterojunctions as the working electrodes with an exposed area of $0.25 \mathrm{~cm}^{2}$, a Pt wire counter electrode, a $\mathrm{Ag} / \mathrm{AgCl}$ reference electrode, and $0.01 \mathrm{~mol} / \mathrm{L} \mathrm{Na}_{2} \mathrm{SO}_{4}$ as the electrolyte [20]. The photocurrent density versus applied voltage scans of the samples were measured at a solar illumination energy of $100 \mathrm{~mW} / \mathrm{cm}^{2}$.

\section{Results and discussion}

\subsection{Fabrication of nanoarchitectures}

We adopted three feasible and straightforward procedures to fabricate the tentative nanoarchitecture of the $0.2 \mathrm{Pd} / 4 \mathrm{Fe} / 3 \mathrm{D}-\mathrm{BiV}$ sample (Figure 1a). Firstly, a technologically facile PMMA-templating approach was used to fabricate the 3D-BiV. Secondarily, amorphous $\mathrm{Fe}_{2} \mathrm{O}_{3}$ nanofilm was deposited on the surface of $3 \mathrm{DOM} \mathrm{BiVO}_{4}$ via an incipient-wetness impregnation route and after a low-temperature annealing process. Finally, plasmonic Pd constituent was loaded on the surface of the $\mathrm{Fe}_{2} \mathrm{O}_{3} / 3 \mathrm{D}$ - $\mathrm{BiV}$ through a bubbling-assisted sol deposition-adsorption process. For that high temperature $\left(>400{ }^{\circ} \mathrm{C}\right)$ was exonerated through the whole preparation, all of the as-obtained 3DOM samples were supposed to possess relative lower crystallization than 
those in the literature $[17,20,30]$, which was considered to benefit the generation of the uniform $\mathrm{Fe}_{2} \mathrm{O}_{3}$ nanofilm and small $\mathrm{Pd}$ sub-nanoclusters as discussed below.

Figure 2 as well as Figures S1-S3 (Supplementary material) shows the SEM and TEM images of $0.2 \mathrm{Pd} / 4 \mathrm{Fe} / 3 \mathrm{D}-\mathrm{BiV}$ and its counterparts. Obviously, the 3D-BiV, 4Fe/3D-BiV, and 0.2Pd/4Fe/3D-BiV samples possessed high-quality 3DOM architecture, whereas the referenced BiV-bulk sample derived from a hydrothermal route [35] displayed a dumbbell-like morphology with a micrometer size. From the SEM images (Figure S4) of the photoelectrodes (i.e., the 3D$\mathrm{BiV}, 4 \mathrm{Fe} / 3 \mathrm{D}-\mathrm{BiV}$, and $0.2 \mathrm{Pd} / 4 \mathrm{Fe} / 3 \mathrm{D}-\mathrm{BiV}$ deposited on ITO glass), one can see that the deposited layers were 500-800 $\mathrm{nm}$ in thickness. As shown in the low-resolution TEM images from different perspectives, the $0.2 \mathrm{Pd} / 4 \mathrm{Fe} / 3 \mathrm{D}-\mathrm{BiV}$ sample retained the well-defined 3DOM structure of 3D-BiV (Figures S1 and S3), but a decrease in surface area $\left(15.1 \mathrm{~m}^{2} / \mathrm{g}\right.$ ) and an increase in pore volume $\left(0.100 \mathrm{~m}^{3} / \mathrm{g}\right)$ were observed as compared to those of the 3D-BiV sample (Table $\mathrm{S} 1$ and Figure S5). The diameters of the periodic macropores were 100-150 nm, much smaller than the average size of PMMA microspheres. This reduction was due to the shrinkage of the 3DOM framework during calcination. The sizes of the secondary windows interconnecting two macropores and the corresponding ligaments were about 50-80 $\mathrm{nm}$ and 20-40 nm, respectively. Such a developed porous structure would facilitate the mass transfer or light diffusion and contribute a lot to the accessibility of the active sites. Surprisingly, when the sample was exposed to the high-energy electron beams, its initially smooth ligament surface became rough, accompanying with the in-situ generation and crystallization of nanoparticles (as indicated in regions I-IV of Figures S1 and S2). According to its corresponding EDX mapping image (Figure 2d) and EELS (Figure S2f) images after crystallization, the in-situ educts (ca. $5 \mathrm{~nm}$ in diameter) might be metallic Bi (JCPDS PDF\# 44-1246), whose lattice spacings ( $d$ values) agreed well with 
those (ca. 0.32 and $0.40 \mathrm{~nm}$ ) of the (012) and (003) lattice planes (Figures S1 and S2), respectively. Similar phenomena also occurred in the other samples, confirming the lowcrystalline surface of the $\mathrm{BiVO}_{4}$ component. It is observed from Figure $\mathrm{S} 1$ that the $d$ values from the ligaments were ca. $0.26,0.30$, and $0.46 \mathrm{~nm}$, respectively, in line with those of the (200), (112), and (011) lattice planes of monoclinic $\mathrm{BiVO}_{4}$ (referring to the XRD results in Figure S6). This result indicates the well crystalline structure of the inner $\mathrm{BiVO}_{4}$ ligament. Furthermore, the TEM and EELS images reveal that the $\mathrm{Fe}_{2} \mathrm{O}_{3}$ phase was uniformly spread on the $\mathrm{BiVO}_{4}$ support (also referring to Figures S1 and S3); however, no sharp XPD peaks were observed even in its bulk sample with a possible $\alpha$ phase (Figure S6), suggesting that the $\mathrm{Fe}_{2} \mathrm{O}_{3}$ film possessed amorphous structure as well. Besides, according to the changed thickness of the ligaments induced by the electron beams (Figure S1), the low-crystalline or amorphous layer was estimated to be $0.5-1 \mathrm{~nm}$ in the thickness, quite beneficial for the generation of intense plasmonic electric fields as mentioned above. However, no obvious Pd nanoparticles were observed on the ligament surface of the 3DOM support, even though the ICP-AES investigation showed that the Pd loading was ca. $0.18 \mathrm{wt} \%$ and the surface $\mathrm{Pd} / \mathrm{Bi}$ atomic ratio was determined to be ca. 0.29 by the XPS technique (Table S1). These results imply the possible formation of quite small Pd subnanoclusters on the above low-crystalline Fe/3D-BiV interface. That is to say, the rough ligament surface should not favour the aggregation and nucleation of Pd. Similar phenomena took place in the Au-loaded sample (Figure S1).

Figure 3 and Table $\mathrm{S} 1$ show the effects of the $\mathrm{Fe}_{2} \mathrm{O}_{3}$ nanofilm and $\mathrm{Pd}$ subnanoclusters on the surface chemical composition of the $0.2 \mathrm{Pd} / 4 \mathrm{Fe} / 3 \mathrm{D}-\mathrm{BiV}$ sample. The XPS doublets at $\mathrm{BE}=159.1$ and $164.3 \mathrm{eV}$ were characteristic of $\mathrm{Bi}^{3+} 4 \mathrm{f}_{7 / 2}$ and $\mathrm{Bi}^{3+} 4 \mathrm{f}_{5 / 2}$ [36], while the shoulders at higher BEs arose from surface $\mathrm{Bi}_{2} \mathrm{O}_{3}$. Similarly, the peaks at $\mathrm{BE}=518.7 \mathrm{eV}$ in the $\mathrm{V} 2 \mathrm{p}_{3 / 2} \mathrm{XPS}$ spectra was associated with surface $\mathrm{V}_{2} \mathrm{O}_{3}$. However, no $\mathrm{V}^{4+}$ but only $\mathrm{V}^{5+}$ species existed on the $\mathrm{V}$ - 
enrichment surface of each $\mathrm{BiVO}_{4}$ sample (Table S1) by judging from the sole peak at $\mathrm{BE}=$ $516.7 \mathrm{eV}[30,31]$. It is noted that, when the samples were pretreated at $500{ }^{\circ} \mathrm{C}$ in oxygen before XPS measurements, the above Bi $4 \mathrm{f}$ and V 2 $\mathrm{p}_{3 / 2}$ XPS peaks both exhibited one symmetrical peak and no such shoulders related to $\mathrm{Bi}_{2} \mathrm{O}_{3}$ or $\mathrm{V}_{2} \mathrm{O}_{3}$ appeared at all (without providing the date here). Apparently, the loading of $\mathrm{Fe}_{2} \mathrm{O}_{3}$ and $\mathrm{Pd}$ also enabled the surface composition of the $\mathrm{BiVO}_{4}$ based ligament to become more simplex. The O 1s XPS spectra of the samples also reflected such an influence. Given a constant $\mathrm{BE}(529.9 \mathrm{eV})$ of surface lattice oxygen $\left(\mathrm{O}_{\text {latt }}\right)$ in $\mathrm{BiVO}_{4}($ referring to the O 1s XPS spectrum of the BiV-bulk sample in Figure S7), one can notice that the peaks of adsorbed oxygen $\left(\mathrm{O}_{\mathrm{ads}}\right)$ originated from either hydroxyl groups $(\mathrm{BE}=531.1-531.6 \mathrm{eV})$ or adsorbed $\mathrm{H}_{2} \mathrm{O}(\mathrm{BE}=532.3-532.6 \mathrm{eV})$ [37] gradually shifted to lower positions through the twice loading. At the same time, it is observed that the initial loading of $\mathrm{Fe}_{2} \mathrm{O}_{3}$ led the $\mathrm{O}_{\text {ads }} / \mathrm{O}_{\text {latt }}$ molar ratio to decrease greatly, while the further loading of Pd enabled it to increase slightly (Table S1). Such a phenomenon was associated with the ever-changing porous structure in view of the low $\mathrm{O}_{\text {ads }} / \mathrm{O}_{\text {latt }}$ molar ratio of BiV-bulk (ca. 0.41) and the different adsorption ability of $\mathrm{Fe}_{2} \mathrm{O}_{3}$ and $\mathrm{Pd}$ $[38,39]$. However, except for the significant rise in the surface Fe/Bi molar ratio from 1.06 to 1.76 , the loading of metallic Pd [40,41] did not influence the $\mathrm{Fe}_{2} \mathrm{O}_{3}$ composition (Figure S7 and Table S1). The surface $\mathrm{Fe}^{2+} / \mathrm{Fe}^{3+}$ molar ratio (ca. 0.88 , and with the surface $\mathrm{Fe}^{2+}$ and $\mathrm{Fe}^{3+}$ species at $\mathrm{BE}$ $=710.6$ and $712.8 \mathrm{eV}$ [42], respectively) was almost unchanged from $0.2 \mathrm{Pd} / 4 \mathrm{Fe} / 3 \mathrm{D}-\mathrm{BiV}$ to 4Fe/3D-BiV . Apparently, the purified surface of $0.2 \mathrm{Pd} / 4 \mathrm{Fe} / 3 \mathrm{D}-\mathrm{BiV}$ would be more beneficial for the charge transfer by reducing the recombination of photogenerated electrons and holes.

\subsection{Optical behavior}

Figure 4a shows the UV-Vis diffuse reflectance spectra (inset) of the samples together with their corresponding $(\alpha h v)^{2}$ versus $h v$ plots according to the formula of $(\alpha h v)^{2}=A\left(h v-E_{\mathrm{g}}\right)$ for a direct-transition semiconductor [30,31,35], in which the $\alpha, h v$, and $A$ present the absorption 
coefficient, incident photon energy, and transition constant, respectively. It is reported that $\mathrm{Fe}_{2} \mathrm{O}_{3}$ has a high absorptive power to red light and distinctive ability to capture and transfer photoinduced electrons [43-46]. Judging from the spectra, the pristine 3D-BiV support showed an $E_{\mathrm{g}}$ of $2.56 \mathrm{eV}$ (Table $\mathrm{S} 1$ ), whereas the loading of $\mathrm{Fe}_{2} \mathrm{O}_{3}$ (with an $E_{\mathrm{g}}$ of $1.88 \mathrm{eV}$ ) could enhance the visible-light $(480-800 \mathrm{~nm})$ absorption and also the content itself exhibited a secondary $E_{\mathrm{g}}$. However, the loading of Pd seemed to decrease the two-tier bandgap energies of 4Fe/3D-BiV by ca. $0.2 \mathrm{eV}$, implying the existence of the plasmonic effect on the optical absorptivity of the composite. Simultaneously, the PL spectra of these samples (Figure 4b) were also collected by using an incident laser wavelength of $514.5 \mathrm{~nm}$ (i.e., $2.41 \mathrm{eV}$ ). Based on the intrinsic or extrinsic defects of the 3D-BiV scaffold, all of the samples exhibited similar emission bands in the visible region. However, the bands were quite different from the homogeneous emission of bulk $\mathrm{BiVO}_{4}$ [47], indicating the particular role of the 3DOM structure in harvesting the light. In particular, the weak yellow band at 577-597 $\mathrm{nm}$ was assigned to the interstitial oxygen and dislocation, and the five green emitting wavelengths (below $577 \mathrm{~nm}$ and 2.38-2.21 eV) were associated with transition between ionized oxygen vacancies and photoexcited holes/electrons close to the conductive band and deeply trapped holes at $\mathrm{V}_{\mathrm{O}}{ }^{++}$, or surface donor and acceptor defects $[48,49]$. Except for the slight stronger red emission, these featured emissions showed that the loading of $\mathrm{Fe}_{2} \mathrm{O}_{3}$ and $\mathrm{Pd}$ would significantly deaden the PL intensity, demonstrating that the $0.2 \mathrm{Pd} / 4 \mathrm{Fe} / 3 \mathrm{D}-$ BiV sample possessed a stronger ability to capture the photoinduced electrons and to suppress the recombination of the photogenerated charge carriers [44-47]. Similar phenomena also took place on the photoelectrode samples (Figure 4c), confirming the existence of a synergistic effect of these components. Besides, accompanied with the intensity attenuation of the Raman peaks of the Pd and $\mathrm{Fe}_{2} \mathrm{O}_{3}$-loaded samples (Figures 4d and S8a), one can observe a blue shift of the main peak 
at $827 \mathrm{~cm}^{-1}$ particularly in the photoelectrode samples, which was due to the symmetric stretching mode of the $\mathrm{V}-\mathrm{O}$ bond in $\mathrm{BiVO}_{4}$. The variational chemical bonds between metal elements (i.e., $\mathrm{Fe}, \mathrm{Bi}$, and $\mathrm{V}$ ) and oxygen can also be declaimed by the FI-IR spectra (Figure S8b). It is apparent that the variation tendency was in good agreement with those obtained from the XPS results and optical behaviors, and further demonstrated the modification of $\mathrm{Fe}_{2} \mathrm{O}_{3}$ and $\mathrm{Pd}$ on the surface of 3D-BiV. Undoubtedly, such a distinctively optical interaction would exert a positive influence on the photocatalytic performance of the $\mathrm{Pd} / \mathrm{Fe}_{2} \mathrm{O}_{3} / 3 \mathrm{D}-\mathrm{BiV}$ hybrid.

\subsection{Photocatalytic performance}

\subsubsection{Powder samples for photocatalytic phenol degradation}

Phenol is a typical probe molecule for the photodegradation due to its harmfulness and intractability, and various mechanisms have been well proposed by recent considerable efforts $[18,50]$. Under visible light irradiation, commercial $\mathrm{TiO}_{2}$ could hardly degrade phenol (only $4 \%$ after $4 \mathrm{~h}$ at phenol concentration $=0.2 \mathrm{~mol} / \mathrm{L}$ ) [30] through a Fenton-type reaction [18]. Even though an enhanced performance could be achieved over $\mathrm{N}$-doped $\mathrm{TiO}_{2}$ [28,51], the photocatalytic activity was still very limited to degrade phenol [51]. Our group improved the phenol conversion to $89 \%$ after $3 \mathrm{~h}$ of visible light illumination over an optimized 3D-BiV with high crystallinity [30]. Though this photocatalyst showed a better activity than those of the welldeveloped materials reported in the literature (e.g., $\mathrm{Fe}_{2} \mathrm{O}_{3} / \mathrm{RGO}$ [43], $\mathrm{Ag} / \mathrm{AgBr} / \mathrm{Bi}_{2} \mathrm{MoO}_{6}$ [52], $\mathrm{Bi}_{2} \mathrm{O}_{3}-\mathrm{Bi}_{2} \mathrm{WO}_{6}$ [53], and $\mathrm{Au} / \mathrm{ZnO}$ [54]; and more performances for the relative photocatalysts can be found in Table S2), it is still far away from the practical photocatalytic application. In this study, as shown in Figures 5 and S9, even doubling the initial phenol concentration to 0.4 $\mathrm{mmol} / \mathrm{L}$, the elaborate $0.2 \mathrm{Pd} / 4 \mathrm{Fe} / 3 \mathrm{D}-\mathrm{BiV}$ material with rational $n-n$ heterojunction, plasmonic effect, and optical or mass transfer configuration (as illustrated in Figure 1b) can completely eliminate the stubborn phenol molecules at a rather high rate. It is well known that, in a Fenton 
reaction, phenol is first transformed into some intermediates over a photocatalyst under the attack of reactive species (e.g., holes $\left(\mathrm{h}^{+}\right)$and $\bullet \mathrm{OH}$ and $\bullet \mathrm{O}^{2-}$ radicals $[50,55]$ ), such as catechol, resorcinol, hydroquinone, and benzoquinone together with the fracture of phenyl rings; and then, these aromatic compounds are photocatalyticly degraded into those short-chain organic acids (e.g., maleic, oxalic, acetic, and formic acids); finally, such small molecules can be easily oxidized into $\mathrm{CO}_{2}$ and $\mathrm{H}_{2} \mathrm{O}$ [50]. In addition, the pathway of hydroquinone formation has been proved to be the rate-determining step for phenol degradation over $\mathrm{TiO}_{2}[17,56]$. In our case, it was found that no peaks of phenol (referring to the $m / z$ ratio $=97$ in Figure S10 obtained by the ESI-MS technique) at $270 \mathrm{~nm}$ appeared on the UV-Vis absorbance spectra. However, one can clearly observe that the peak (at $286 \mathrm{~nm}$ ) intensity of hydroquinone (the $\mathrm{m} / \mathrm{z}$, ratio $=109)$ first rose up and then went down, indicating the initial conversion of phenol to hydroquinone and other intermediates (referring to the peaks at 320 and $448 \mathrm{~nm}$ and the $\mathrm{m} / \mathrm{z}$ ratio $=124$ and 131) and the subsequent decomposition of the intermediates $[18,47,50,56]$. Obviously, such a stepwise phenomenon over the $3 \mathrm{D}-\mathrm{BiV}$ with low-crystalline surface was quite different from the direct degradation of phenol over those semiconductors with high crystallinity, suggesting the photocatalytic potential of the stepped phragmoid surface. As expected, no characteristic peaks due to phenylic fragments and other compounds were detected in the final solutions of the $0.2 \mathrm{Pd} / 4 \mathrm{Fe} / 3 \mathrm{D}-\mathrm{BiV}$ and $4 \mathrm{Fe} / 3 \mathrm{D}-\mathrm{BiV}$ samples, confirming the complete degradation of organic compounds after visible light irradiation.

To better compare the performances of $0.2 \mathrm{Pd} / 4 \mathrm{Fe} / 3 \mathrm{D}-\mathrm{BiV}$ and its counterparts, the curves of the absorbance (i.e., the peak intensity of hydroquinone) versus wavelength at different irradiation time over the representative samples were plotted in Figure 5. It can be seen that the formation time (ca. $10 \mathrm{~min}$ ) and degradation time (<90 $\mathrm{min}$ ) of hydroquinone over 0.2Pd/4Fe/3D-BiV were both the shortest, which were ca. $30 \mathrm{~min}$ and $<120 \mathrm{~min}$ over 4Fe/3D$\mathrm{BiV}$, and ca. $60 \mathrm{~min}$ and > $180 \mathrm{~min}$ over $3 \mathrm{D}-\mathrm{BiV}$, respectively. The results illustrate the 
extraordinary positive roles of $\mathrm{Fe}_{2} \mathrm{O}_{3}$ and $\mathrm{Pd}$ in enhancing photocatalytic performance of the 3DBiV sample. In particular, on one hand, the uniform $\mathrm{Fe}_{2} \mathrm{O}_{3}$ nanofilms could not only bring about a number of heterojunctions and much light absorption, but also can play a role of a classical Fenton reagent in reacting with $\mathrm{H}_{2} \mathrm{O}_{2}$ to yield $\bullet \mathrm{OH}$ radicals, as confirmed by the two greatly increased conversion rates over the $4 \mathrm{Fe} / 3 \mathrm{D}-\mathrm{BiV}$ sample; and, thanks to the prominent capability of plasmonic Pd subnanoclusters to gather light and electrons, the whole degradation of phenol was greatly accelerated. On the other hand, there was a new peak at $448 \mathrm{~nm}$ over the $4 \mathrm{Fe} / 3 \mathrm{D}-\mathrm{BiV}$ sample, whose intensity was further enhanced after loading Pd. In view of the evolution of these stronger peaks and the much shorter conversion time, it is reasonable to deduce that loading $\mathrm{Fe}_{2} \mathrm{O}_{3}$ and Pd can lead to the fast photocatalytic generation of another phenol derivative, which could be more easily degraded into small fat molecules and further into $\mathrm{CO}_{2}$ and $\mathrm{H}_{2} \mathrm{O}$. In addition, one can also observe that the maximum peak intensity assigned to hydroquinone was variable for each sample. Particularly, the $0.2 \mathrm{Pd} / 4 \mathrm{Fe} / 3 \mathrm{D}-\mathrm{BiV}$ sample showed the lowest intensity, while the 4Fe/3D-BiV sample exhibited the highest intensity. This result suggests the generation, accumulation, and consumption of hydroquinone in the individual reaction solution. For instance, the generation rate of hydroquinone was much faster than its consumption rate over $4 \mathrm{Fe} / 3 \mathrm{D}-\mathrm{BiV}$, which brought about a higher accumulation of hydroquinone in the solution and hence a much stronger absorbency of the solution. The regular red or blue shift of the specific wavelength assigned to the maximum absorbance (Figures 5 and S9) also reflected such a degradation process, in line with the as-proposed mechanism of phenol degradation in the literature $[18,50,56]$. By comparing the results shown in Figures $S 9$ and S10, one can further realize that the photocatalyst as well as the small amount of $\mathrm{H}_{2} \mathrm{O}_{2}$ played indispensable roles during the degradation, in good agreement with the previous results. Moreover, one can also notice the 
catalytic selectivity [15] of phenol degradation and the good photocatalytic stability of this kind of photocatalysts (see Supplementary material).

\subsubsection{Photoanodes for water splitting}

The unique nanoarchitecture of the 3D-BiV-based materials not only exhibits a great potential in photocatalytic removal of organics (i.e., mainly using the photogenerated holes with the help of an electron scavenger like $\mathrm{H}_{2} \mathrm{O}_{2}$ ), but also is favorable for promoting the sunlight-driven water splitting (which greatly depends on the utilization of the photogenerated electrons with a hole scavenger). As one more advanced and efficient photocatalytic technique, the PEC water splitting is more ready to reflect the potential of a photocatalytic material in practice application. There are several works in the literature to proclaim the potential $\mathrm{PEC}$ property of $\mathrm{BiVO}_{4}$ with a favorable conduction band edge position near the thermodynamic $\mathrm{H}_{2}$ evolution potential [57]. Up to now, tremendous efforts have been made to improve the poor electron-hole separation ability of $\mathrm{BiVO}_{4}$ for better performance, including doping elements, constructing heterojunctions, merging oxygen evolution catalysts (OECs), and forming competitive morphologies and architectures. According to Ye et al. [58] who summarized the recent key advances in $\mathrm{BiVO}_{4}$-based photoanodes for PEC solar water splitting, the highest current density without the use of OECs has so far been up to ca. $1.5 \mathrm{~mA} / \mathrm{cm}^{2}$ at $0.4 \mathrm{~V}$ (vs. $\mathrm{Ag} / \mathrm{AgCl}$ ). Up to date, the efficient PEC properties of some 3DOM photoelectrodes for water splitting have also been extensively studied. For example, under visible light irradiation, a $\mathrm{H}_{2}$ evolution rate of ca. $20.5 \mu \mathrm{mol} /(\mathrm{g} \mathrm{h})$ was reported over a 3DOM N-doped $\mathrm{TiO}_{2}$ sample [28]. In particular for the $3 \mathrm{DOM} \mathrm{BiVO}_{4}$-based system that we are interested in, we noticed that under solar light irradiation and at $0.4 \mathrm{~V}$ (vs. $\mathrm{Ag} / \mathrm{AgCl})$, the photocurrents reached ca. $0.38 \mathrm{~mA} / \mathrm{cm}^{2}$ over a pure $\mathrm{BiVO}_{4}$ sample with adjustable dual porosity [59], ca. $0.75 \mathrm{~mA} / \mathrm{cm}^{2}$ over a Mo-modified $\mathrm{BiVO}_{4}$ sample [60], and ca. $0.42 \mathrm{~mA} / \mathrm{cm}^{2}$ over a $\mathrm{Au} / \mathrm{Mo}$ co-modified $\mathrm{BiVO}_{4}$ sample (with evolution rates of $\mathrm{H}_{2}$ and $\mathrm{O}_{2}$ at $7.7 \pm 0.2$ and $3.8 \pm 0.2 \mu \mathrm{mol} /\left(\mathrm{cm}^{2} \mathrm{~h}\right.$ ) simultaneously) 
[61], respectively. In view of all of these results, in the present study, we did not further optimize the materials (e.g., by simply increasing the thickness of the active material on the ITO glass) but just presented the semi-qualitative performance results (Figure 5) under the same experimental conditions to illustrate the superiority of the as-proposed hybrid nanoarchitecture, namely its distinguished ability to exploit the photoinduced electrons.

As pointed out in the previous report [59-61], the 3D ordered macro-/mesoporous architecture has advantages in promoting charge migration in the bulk and on the surface. In our case, when a thin $\mathrm{Fe}_{2} \mathrm{O}_{3}$ layer was deposited on the low-crystalline surface of $3 \mathrm{D}-\mathrm{BiV}$, a much enhanced photocurrent density (Figure 6a) was obtained in the bias range of -0.1 to $0.3 \mathrm{~V}$ (vs. $\mathrm{Ag} / \mathrm{AgCl}$ ), which reached a maximal photocurrent density of $0.2 \mathrm{~mA} / \mathrm{cm}^{2}$ at $0.02 \mathrm{~V}$, nearly twice of that over 3D-BiV. That is to say, due to the narrower band gap of the composite and the enhanced light absorbance as well as the formed heterojunction interface, a more amount of charge carriers could be generated over the $\mathrm{Fe}_{2} \mathrm{O}_{3} / 3 \mathrm{D}-\mathrm{BiV}$ system, and the photoinduced electrons could be more effectively transferred from the $n-n$ heterojunction to the counter electrode via the external circuit. As revealed previously in both experimental and theoretical studies for water splitting [57,58,61,62], a larger photocurrent always stands for more output of $\mathrm{H}_{2}$ or $\mathrm{O}_{2}$, namely a higher PEC activity. Benefited from the easier separation of photoinduced charge carriers by the internal electrostatic field at the junction region, a more amount of holes also possibly participate in the reaction instead of recombination with electrons [20]. However, a relative obvious decline appeared in the photocurrent density versus potential curve of $\mathrm{Fe}_{2} \mathrm{O}_{3} / 3 \mathrm{D}-\mathrm{BiV}$ simultaneously. About this phenomenon, it has been reported that with the rise in bias potential, the internal electrostatic field would be weakened due to the simutanously decreased thickness of the space charge layer. As a result, less electron-hole pairs could be separated and the photocurrent density decreased $[63,64]$. This explanation can be further substantiated by the photoelectric response of 
the $\mathrm{Pd} / \mathrm{Fe}_{2} \mathrm{O}_{3} / 3 \mathrm{D}-\mathrm{BiV}$ sample. The decay was greatly alleviated and the subsequent photocurrent was much enhanced by the plasmonic electric field derived from the Pd subnanoclusters. The same deduction can be made from their photoconversion efficiency (Figure 6b) calculated according to the equation: $\eta=\left|j_{p}\right| \times(0.63-|V|) / I_{0}$, where $j_{p}\left(\mathrm{~mA} / \mathrm{cm}^{2}\right)$ is the photocurrent density under an applied bias $V(\mathrm{~V})$ versus $\mathrm{Ag} / \mathrm{AgCl}$ and $I_{0}\left(\mathrm{~mW} / \mathrm{cm}^{2}\right)$ is the power density of incident light [65]. Basically, no striking rise in maximum photoconversion efficiency (ca. $0.12 \%$ ) was observed over the $\mathrm{Fe}_{2} \mathrm{O}_{3} / 3 \mathrm{D}-\mathrm{BiV}$ sample before and after Pd loading. However, a positive shift of the onset potential (Fermi energy level) took place over the $\mathrm{Pd} / \mathrm{Fe}_{2} \mathrm{O}_{3} / 3 \mathrm{D}-\mathrm{BiV}$ sample, suggesting that the electrons accumulating in the heterojunctions were reduced due to the introduction of Pd. To gain deep insights into this phenomenon, electrochemical impedance spectroscopy (EIS) was applied to study the interface charge transfer kinetics. As presented in the Nyquist plots (Figure S12), besides a usual semicircle part (related to charge transfer resistance) and a straight line part (corresponding to mass transfer resistance), along with the loading of $\mathrm{Fe}_{2} \mathrm{O}_{3}$ and $\mathrm{Pd}$, another semicircle arc appeared and became obvious, indicating that the charge transfer resistance controlled the kinetics at the interface. Meanwhile, one can notice the better charge transfer ability from the smaller radium of arc [20]. The synergistic improvement could be further proved by the transient photoresponse at a fixed bias potential of $0.2 \mathrm{~V}$ (vs. $\mathrm{Ag} / \mathrm{AgCl}$ ) via several "on-off" cycles of irradiation (Figure 6c). The photocurrent density of each sample (ca. 0.08, 0.11 , and $0.19 \mathrm{~mA} / \mathrm{cm}^{2}$ for $3 \mathrm{D}-\mathrm{BiV}, \mathrm{Fe}_{2} \mathrm{O}_{3} / 3 \mathrm{D}-\mathrm{BiV}$, and $\mathrm{Pd} / \mathrm{Fe}_{2} \mathrm{O}_{3} / 3 \mathrm{D}-\mathrm{BiV}$, respectively) exhibited a rapid and reversible response during the "on" and "off" switching. It should be noticed that under irradiation, the photocurrent increased much faster on the samples modified by $\mathrm{Fe}_{2} \mathrm{O}_{3}$ and further by Pd, indicating that the mobility and separation of charge carriers could be effectively enhanced by creating an electrical field. For that the inner defects and boundaries tend to become preferable sites where electrons and holes are easy to recombine [66], the occupation 
of the amorphous $\mathrm{Fe}_{2} \mathrm{O}_{3}$ nanofilms and plasmonic Pd subnanoclusters on these sites can greatly alleviate the recombination of the photogenerated electrons and holes [60]. This carrier storage effect could be more distinct under steady irradiation at a bias of $0.6 \mathrm{~V}$ (vs. $\mathrm{Ag} / \mathrm{AgCl}$ ). As shown in Figure $6 \mathrm{~d}$, the photocurrent density reached $0.56 \mathrm{~mA} / \mathrm{cm}^{2}$ after equilibration, which was 3.5 and 9.3 times higher than those of $\mathrm{Fe}_{2} \mathrm{O}_{3} / 3 \mathrm{D}-\mathrm{BiV}$ and $3 \mathrm{D}-\mathrm{BiV}$, respectively. Apparently, the plasmonic effect was quite effective and rather crucial for the enhancement of PEC activity. Based on the above results, we believe that constructing such a synergistic nanoarchitecture with the heterogeneous structure, stepped phragmoid surface, and plasmonic metallic nanostructure on 3DOM nanoarchitecture is also a promising strategy for achieving high efficiency in PEC water splitting.

Last but not the least, in heterogeneous photocatalysis, it is generally accepted that high crystallinity is beneficial to photocatalysis, taking into account that the rapid recombination of excited carriers could be deterred. However, in the present study, one can see that even with much lower crystallinity than those traditional photocatalysts, the hybrid interface constructed by visible-light-response $\mathrm{BiVO}_{4}$ with low crystalline surface and amorphous $\mathrm{Fe}_{2} \mathrm{O}_{3}$ nanofilm could efficiently harvest the visible light owing to the establishment of two-tier band gaps and utilize the photogenerated charge carriers due to the widespread "electric field" (i.e., the heterojunctions), in particular when Pd subnanoclusters were further induced into this catalyst system to purify the $\mathrm{BiVO}_{4}$ surface and induce the plasmonic effect. Furthermore, due to the abundant adsorption and active sites as well as the instant mass transfer and light propagation over the 3DOM framework, such an integrated photocatalyst exhibited much enhanced activity either in phenol degradation or in water splitting (i.e., the high-efficient utilization for both of the electrons and holes). That is to say, a synergistic design (e.g., the construction of intense "electric field" at the sub-nanoscale interface in this study) may turn the low crystallinity adverse to traditional photocatalysis into an 
advantage, since it should mean better adsorption capacity and more reaction sites for molecules at the same time. Consequently, we would like to highlight the great potential of the construction of low-crystalline plasmonic heterointerfaces in promoting the photocatalytic performance, as schematically shown in Figure 1a.

\section{Conclusion}

To summarize, through harmonizing various outstanding photocatalytic features, such as the optical 3DOM framework, the abundant heterojunctions, and the plasmonic effects, we have developed one integrated photocatalyst $\mathrm{Pd} / \mathrm{Fe}_{2} \mathrm{O}_{3} / 3 \mathrm{DOM}-\mathrm{BiVO}_{4}$. It not only possesses high visible light harvesting ability, but also can efficiently separate and transfer the photogenerated carriers to drive the chemical reactions at the interface (i.e., the fast degradation of highconcentration phenol in wastewater and the enhanced efficiency of water splitting). Interfacial studies show that the modification of amorphous $\mathrm{BiVO}_{4}$ by $\mathrm{Fe}_{2} \mathrm{O}_{3}$ nanofilms and plasmonic $\mathrm{Pd}$ subnanoclusters could significantly improve the low-crystalline surface of $3 \mathrm{DOM} \mathrm{BiVO}_{4}$ in the composition (e.g., the active $\mathrm{V}-\mathrm{O}$ bond) and photoelectricity property, thus contributing a highly synergistic interface to exploit carries for photocatalytic reactions. Consequently, both of the synthetic strategy for such structured materials and the designing idea would pave a way to the sunlight-driven photocatalysts with high efficiency.

\section{Acknowledgements}

This work was supported by the NSF of China (21377008) and Doctoral Innovation Fund of Beijing University of Technology (YB201310). Dr. Kemeng Ji acknowledges the financial support from AIMR in Tohoku University and the JSPS fellowship program in Japan (16J06828). We also acknowledge Prof. Mingwei Chen from Tohoku University and Dr. Lihua Wang from Beijing University of Technology for experimental assistance and helpful discussion. 


\section{Appendix A. Supporting information}

Supplementary data associated with this article can be found, in the online version, at http://dx.doi.org/10.1016/j.nanoenergy.2016.XX.XXX.

\section{References}

[I] F. Wang, C.H. Li, H.J. Chen, R.B. Jiang, L.D. Sun, Q. Li, J.F. Wang, J.C. Yu, C.H. Yan, J. Am. Chem. Soc. 135 (2013) 5588-5601.

[2] M.Y. Wang, J. Ioccozia, L. Sun, C.J. Lin, Z.Q. Lin, Energy Environ. Sci. 7 (2014) 2182-2202.

[3] X.B. Chen, L. Liu, P.Y. Yu, S.S. Mao, Science 331 (2011) 746-751.

[4] S. Linic, P. Christopher, D.B. Ingram, Nature Mater. 10 (2011) 911-921.

[5] A. Kudo, K. Ueda, H. Kato, I. Mikami, Catal. Lett. 53 (1998) 229-230.

[6] R.W. Hess, U.S. Patent no 4115142 (1978).

[7] K. Pingmuang, N. Wetchakun, W. Kangwansupamonkon, K. Ounnunkad, B. Inceesungvorn, S. Phanichphant, Int. J. Photoenergy 2013 (2013) 943256.

[8] T. Saison, N. Chemin, C. Chaneac, O. Durupthy, V. Ruaux, L. Mariey, F. Mauge, P. Beaunier, J.P. Jolivet, J. Phys. Chem. C 115 (2011) 5657-5666.

[9] P. Ju, P. Wang, B. Li, H. Fan, S.Y. Ai, D. Zhang, Y. Wang, Chem. Eng. J. 236 (2014) 430437.

[10] H.M. Torres Galvis, J.H. Bitter, C.B. Khare, M. Ruitenbeek, K.P. de Jong, Science 33 (2012) $835-883$.

[11] R. Zboril, M. Mashlan, D. Petridis, Chem. Mater. 8 (2002) 969-982.

[12] P. Cai, S.-M. Zhou, D.-K. Ma, S.-N. Liu, W. Chen, S.-M. Huang, Nano-Micro Lett. 7 (2015) 183-193.

[13] W.B. Hou, S.B. Cronin, Adv. Funct. Mater. 23 (2013) 1612-1619. 
[14] I. Thomann, B.A. Pinaud, Z.B. Chen, B.M. Clemens, T.F. Jaramillo, M.L. Brongersma, Nano Lett. 11 (2011) 3440-3446.

[15] S.U. Lee, J.W. Hong, S. Choi, S.W. Han, J. Am. Chem. Soc. 136 (2014) 5221-5224.

[16] R. Marschall, Adv. Funct. Mater. 24 (2014) 2421-2440.

[17] R.G. Li, H.X. Han, F.X. Zhang, D.G. Wang, C. Li, Energy Environ. Sci. 7 (2014) 13691376.

[18] R. Su, R. Tiruvalam, Q. He, N. Dimitratos, L. Kesavan, C. Hammond, J.A. Lopez-Sanchez, R. Bechstein, C.J. Kiely, G.J. Hutchings, F. Besenbacher, ACS Nano 6 (2012) 6284-6292.

[19] H. Tada, T. Mitsui, T. Kiyonaga, T. Akita, K. Tanaka, Nature Mater. 5 (2006) 782-786.

[20] Y. Hou, F. Zuo, A. Dagg, P. Feng, Nano Lett. 12 (2012) 6464-6473.

[21] J.K. Matthew, T. Avanesian, P. Christopher, ACS Catal. 4 (2014) 116-128.

[22] P. Christopher, H.L. Xin, A. Marimuthu, S. Linic, Nature Mater. 11 (2012) 1044-1050.

[23] C.T. Dinh, H. Yen, F. Kleitz, T.O. Do, Angew. Chem. Int. Ed. 53 (2014) 6618-6623.

[24] X.L. Zhuo, X.Z. Zhu, Q. Li, Z. Yang, J.F. Wang, ACS Nano 9 (2015) 7523-7535.

[25] W.Y. Lei, T.T. Zhang, L. Gu, P. Liu, J.A. Rodriguez, G. Liu, M.H. Liu, ACS Catal. 5 (2015) $4385-4393$.

[26] B.F. Luo, D.B. Xu, D. Li, G.L. Wu, M.M. Wu, W.D. Shi, M. Chen, ACS Appl. Mater. Interfaces 7 (2015) 17061-17069.

[27] S.C. Glotzer, M. J. Solomon, Nature Mater. 6 (2007) 557-562.

[28] T. Wang, X. Q. Yan, S. S. Zhao, B. Lin, C. Xue, G. D. Yang, S. J. Ding, B. L. Yang, C. S. Ma, G. Yang, G. R. Yang, J. Mater. Chem. A 2 (2014) 15611-15619.

[29] K.M. Ji, J.G. Deng, H.J. Zang, J.H. Han, H. Arandiyan, H.X. Dai, Appl. Catal. B 165 (2015) $285-295$.

[30] Y.X. Liu, H.X. Dai, J.G. Deng, L. Zhang, C.T. Au, Nanoscale 4 (2012) 2317-2325. 
[31] K.M. Ji, H.X. Dai, J.G. Deng, H.J. Zang, H. Arandiyan, S.H. Xie, H.G. Yang, Appl. Catal. B $168-169$ (2015) 274-282.

[32] J.H. Moon, S. Yang, Chem. Rev. 110 (2010) 547-574.

[33] O.H. Kim, Y.H. Cho, S.H. Kang, H.Y. Park, M. Kim, J.W. Lim, D.Y. Chung, M.J. Lee, H. Choe, Y.E. Sung, Nature Commun. 4 (2013) 2473.

[34] Z.W. Seh, S.H. Liu, M. Low, S.Y. Zhang, Z.L. Liu, A. Mlayah, M.Y. Han, Adv. Mater. 24 (2012) 2310-2314.

[35] H.Y. Jiang, H.X. Dai, X. Meng, K.M. Ji, L. Zhang, J.G. Deng, Appl. Catal. B 105 (2011) $326-334$.

[36] S.H. Im, Y.T. Lim, D.J. Suh, O.O. Park, Adv. Mater. 14 (2002) 1367-1369.

[37] H.S. Casalongue, S. Kaya, V. Viswanathan, D.J. Miller, D. Friebel, H.A. Hansen, J.K. Nørskov, A. Nilsson, H. Ogasawara, Nature Commun. 4 (2013) 2817.

[38] Y.C. Wei, J. Liu, Z. Zhao, Y.S. Chen, C.M. Xu, A.J. Duan, G.Y. Jiang, H. He, Angew. Chem. Int. Ed. 50 (2011) 2326-2329.

[39] C.R. Chang, X.F. Yang, B. Long, J. Li, ACS Catal. 3 (2013) 1693-1699.

[40] N.H. Turner, A. M. Single, Surf. Interface Anal. 15 (1990) 215-222.

[41] J.M. Tura, P. Regull, L. Victori, M.D. Castellar, Surf. Interface Anal. 11 (1988) 447-449.

[42] R.Z. Zhang, H.X. Dai, Y.C. Du, L. Zhang, J.G. Deng, Y.S. Xia, Z.X. Zhao, X. Meng, Y.X. Liu, Inorg. Chem. 50 (2011) 2534-2544.

[43] G.K. Pradhan, D.K. Padhi, K.M. Parida, ACS Appl. Mater. Interfaces 5 (2013) 9101-9110.

[44] J.C. Yu, J.G. Yu, W.K. Ho, Z.T. Jiang, L.Z. Zhang, Chem. Mater. 14 (2002) 3808-3816.

[45] T.T. Li, L.H. Zhao, Y.M. He, J. Cai, M.F. Luo, J.J. Lin, Appl. Catal. B 129 (2013) 255-263.

[46] Q.J. Xiang, J.G. Yu, P.K. Wong, J. Colloid. Interface Sci. 357 (2011) 163-167. 
[47] S. Chala, K. Wetchakun, S. Phanichphant, B. Inceesungvorn, N. Wetchakun, J. Alloys Compd. 597 (2014) 129-135.

[48] Ü. Özgür, Y. Alivov, C. Liu, A. Teke, M. Reshchikov, S. Doğan, V. Avrutin, S.-J. Cho, H. Morkoc, J. Appl. Phys. 98 (2005) 041301.

[49] H.B. Zeng, G.T. Duan, Y. Li, S.K. Yang, X.X. Xu, W.P. Cai, Adv. Funct. Mater. 20 (2010) $561-572$.

[50] E. Grabowska, J. Reszczyńska, A. Zaleska, Water Res. 46 (2012) 5453-5471.

[51] M.A. Mohamed, W.N. W. Salleh, J. Jaafar, A.F. Ismail, N.A.M. Nor, Mater. Chem. Phys. 162 (2015) 113-123.

[52] G.H. Tian,Y.J. Chen, X.Y. Meng, J. Zhou, W. Zhou, K. Pan, C.G. Tian, Z.Y. Ren, H.G. Fu, ChemPlusChem 78 (2013) 117-123.

[53] Y. Peng, M. Yan, Q.-G. Chen, C.-M. Fan, H.-Y. Zhou, A.-W. Xu, J. Mater. Chem. A 2 (2014) 8517-8524.

[54] C.G. Silva, M.J. Sampaio, S.A.C. Carabineiro, J.W.L. Oliveira, D.L. Baptista, R. Bacsa, B.F. Machado, P. Serp, J.L. Figueiredo, A.M.T. Silva, J.L. Faria, J. Catal. 316 (2014) 182-190.

[55] M. Sadakane, K. Sasaki, H. Kunioku, B. Ohtani, R. Abe, W. Ueda, J. Mater. Chem. 20 (2010) $1811-1818$.

[56] X.Q. Wang, L. Sø, R. Su, S. Wendt, P. Hald, A. Mamakhel, C. Yang, Y.D. Huang, B.B. Iversen, F. Besenbacher, J. Catal. 310 (2014) 100-108.

[57] T.W. Kim, K.-S. Choi, Science 343 (2014) 990-994.

[58] K.-H. Ye, Z.S. Chai, J.W. Gu, X. Yu, C.X. Zhao, Y.M. Zhang, W.J. Mai, Nano Energy 18 (2015) 222-231.

[59] M. Zhou, H.B. Wu, J. Bao, L. Liang, X.W. Lou, Y. Xie, Angew. Chem. Int. Ed. 52 (2013) 8579-8583. 
[60] M. Zhou, J. Bao, Y. Xu, J.J. Zhang, J.F. Xie, M.L. Guan, C.L. Wang, L.Y. Wen, Y. Lei, Y. Xie, ACS Nano 8 (2014) 7088-7098.

[61] L.W. Zhang, C.-Y. Lin, V.K. Valev, E. Reisner, U. Steiner, J.J. Baumberg, Small 10 (2014) 3970-3978.

[62] L.L. Wang, J. Ge, A.L. Wang, M.S. Deng, X.J. Wang, S. Bai, R. Li, J. Jiang, Q. Zhang, Y. Luo, Y.J. Xiong, Angew. Chem. Int. Ed. 53 (2014) 5107-5111.

[63] Y. Chen, J.C. Crittenden, S. Hackney, L. Sutter, D.W. Hand, Environ. Sci. Technol. 39 (2005) 1201-1208.

[64] H. Yu, X. Quan, S. Chen, H.J. Zhao, J. Phys. Chem. C 111 (2007) 12987-12991.

[65] Z. Chen, T.F. Jaramillo, T.G. Deutsch, A. Kleiman-Shwarsctein, A.J. Forman, N. Gaillard, R. Garland, K. Takanabe, C. Heske, M. Sunkara, E.W. McFarland, K. Domen, E.L. Miller, J.A. Turner, H.N. Dinh, J. Mater. Res. 25 (2010) 3-16.

[66] Y. Lin, Y. Xu, M.T. Mayer, Z.I. Simpson, G. McMahon, S. Zhou, D. Wang, J. Am. Chem. Soc. 134 (2012) 5508-5511. 


\section{Captions of Figures}

Figure 1. Schematic illustration of (a) fabrication of the 3DOM plasmonic heterogeneous photocatalyst $\mathrm{Pd} / \mathrm{Fe}_{2} \mathrm{O}_{3} / \mathrm{BiVO}_{4}$, and (b) its heterojunction structure together with phenol degradation over its 3DOM framework under visible light irradiation.

Figure 2. Microstructure and chemical composition of (a, b) TEM, (c) BF-STEM, and (d) EDX mapping images of $0.2 \mathrm{Pd} / 4 \mathrm{Fe} / 3 \mathrm{D}-\mathrm{BiV}$.

Figure 3. XPS analysis of (a) Bi 4f, (b) V 2 $\mathrm{p}_{3 / 2}$, and (c) O 1s XPS spectra of (I) 0.2Pd/4Fe/3D$\mathrm{BiV}$, (II) 4Fe/3D-BiV, and (III) 3D-BiV.

Figure 4. Optical behaviors of (a) UV-Vis diffuse reflectance spectra (inset) together with plots of $(\alpha h v)^{2}$ versus $h v$ and (b) PL spectra of the powder samples $(0.2 \mathrm{Pd} / 4 \mathrm{Fe} / 3 \mathrm{D}-\mathrm{BiV}, 4 \mathrm{Fe} / 3 \mathrm{D}-\mathrm{BiV}$, 3D-BiV, and Fe-bulk), (c) PL spectra and (d) laser Raman of various photoelectrode samples $\left(\mathrm{Pd} / \mathrm{Fe}_{2} \mathrm{O}_{3} / 3 \mathrm{D}-\mathrm{BiV}, \mathrm{Pd} / 3 \mathrm{D}-\mathrm{BiV}, \mathrm{Fe}_{2} \mathrm{O}_{3} / 3 \mathrm{D}-\mathrm{BiV}\right.$, and $\left.3 \mathrm{D}-\mathrm{BiV}\right)$ on ITO glass.

Figure 5. Photocatalytic performance of $0.2 \mathrm{Pd} / 4 \mathrm{Fe} / 3 \mathrm{D}-\mathrm{BiV}, 4 \mathrm{Fe} / 3 \mathrm{D}-\mathrm{BiV}$, and $3 \mathrm{D}-\mathrm{BiV}$ for phenol degradation under visible-light $(\lambda>400 \mathrm{~nm})$ irradiation, respectively. (a-c) Absorbance as well as maximal absorbance versus wavelength over the 3DOM-structured samples for the degradation of phenol $\left(C_{0}=0.4 \mathrm{mmol} / \mathrm{L}\right)$ aqueous solution at different reaction time, and (d) maximal absorbance and its corresponding absorption wavelength versus irradiation time over the 3DOM-structured samples.

Figure 6. PEC water splitting performance of various photoelectrode samples in $0.01 \mathrm{~mol} / \mathrm{L}$ $\mathrm{Na}_{2} \mathrm{SO}_{4}$ electrolyte under light irradiation of (a) variation of photocurrent density versus applied voltage, (b) photoconversion efficiency as a function of applied potential, (c) transient photocurrent density versus time, and (d) transient photocurrent responses under visible light. 
a Preparation of $\mathrm{Pd} / \mathrm{Fe}_{2} \mathrm{O}_{3} / 3 \mathrm{DOM} \mathrm{BiVO}_{4}$
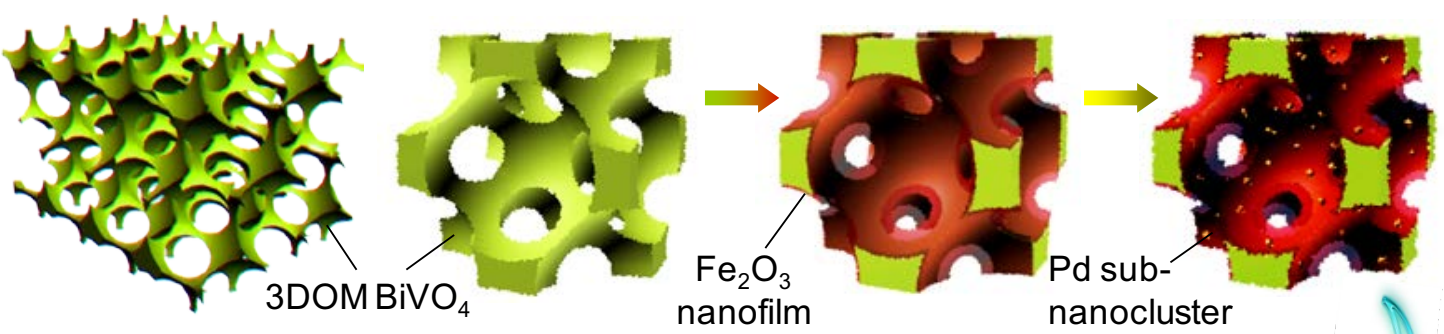

b Visible-light-driven photocatalytic
degradation of phenol

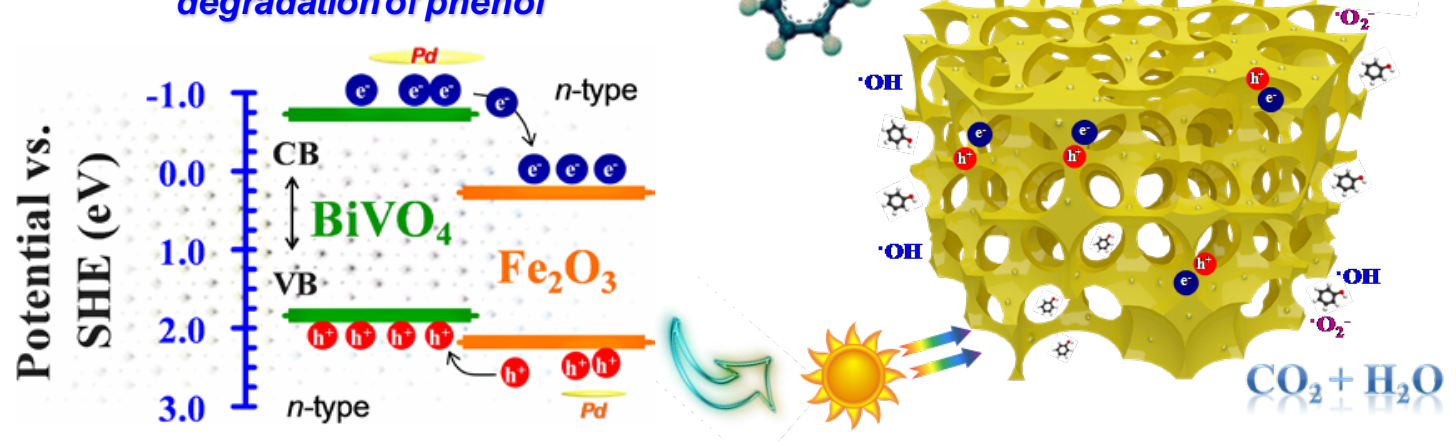

Figure 1. Schematic illustration of (a) fabrication of the 3DOM plasmonic heterogeneous photocatalyst $\mathrm{Pd} / \mathrm{Fe}_{2} \mathrm{O}_{3} / \mathrm{BiVO}_{4}$, and (b) its heterojunction structure together with phenol degradation over its 3DOM framework under visible light irradiation. 


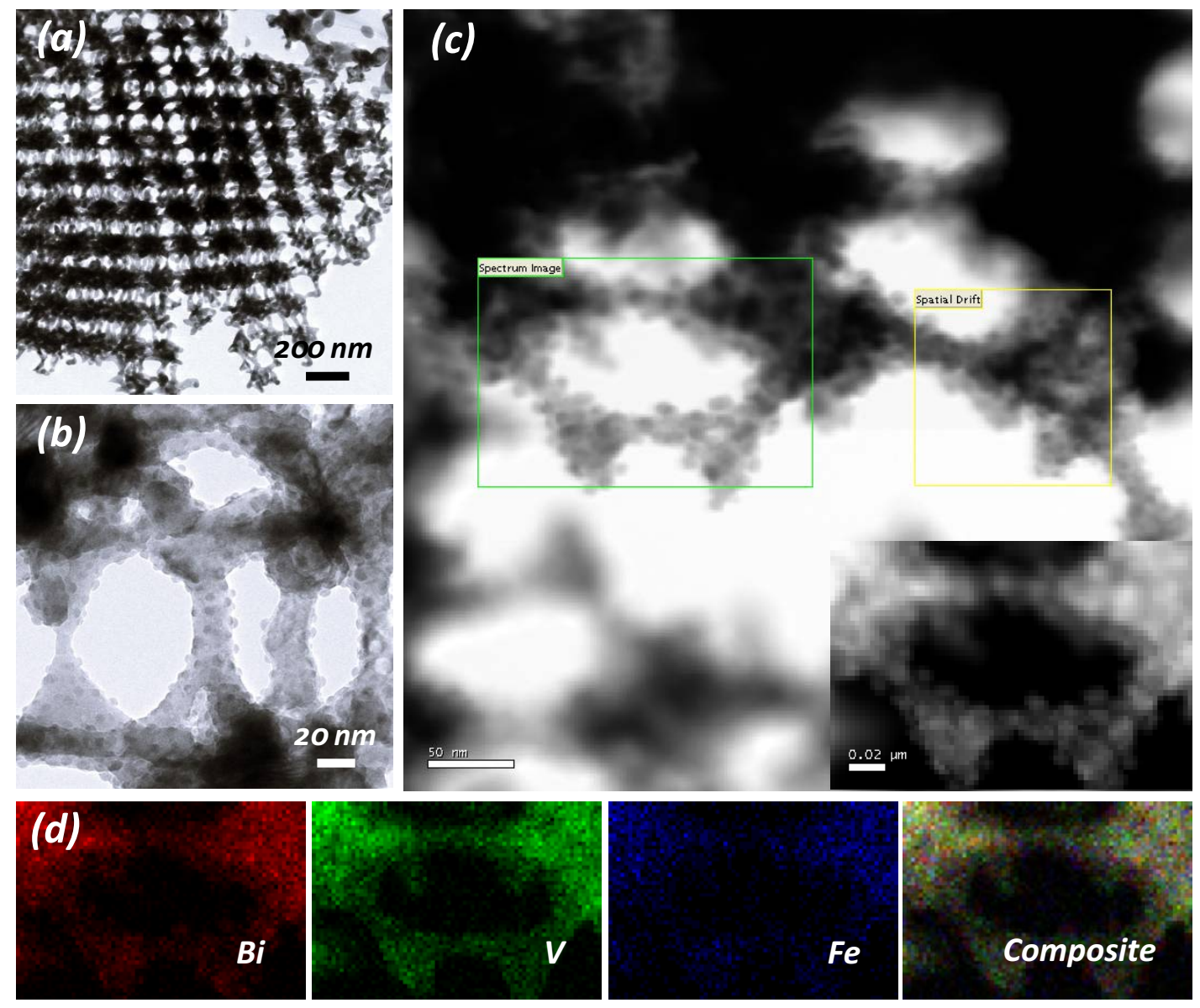

Figure 2. Microstructure and chemical composition of (a, b) TEM, (c) BF-STEM, and (d) EDX mapping images of $0.2 \mathrm{Pd} / 4 \mathrm{Fe} / 3 \mathrm{D}-\mathrm{BiV}$. 
Figure 3. XPS analysis of (a) Bi 4f, (b) V 2 $\mathrm{p}_{3 / 2}$, and (c) $\mathrm{O}$ 1s XPS spectra of (I) $0.2 \mathrm{Pd} / 4 \mathrm{Fe} / 3 \mathrm{D}-\mathrm{BiV}$, (II) 4Fe/3D-BiV, and (III) 3D-BiV.
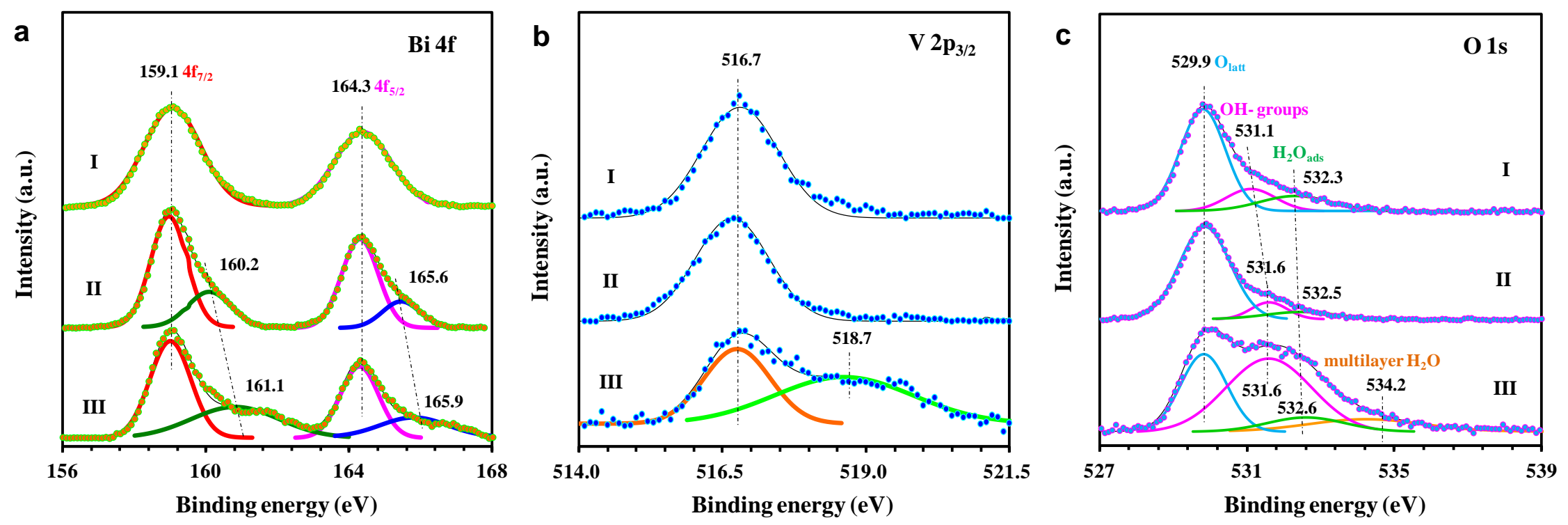

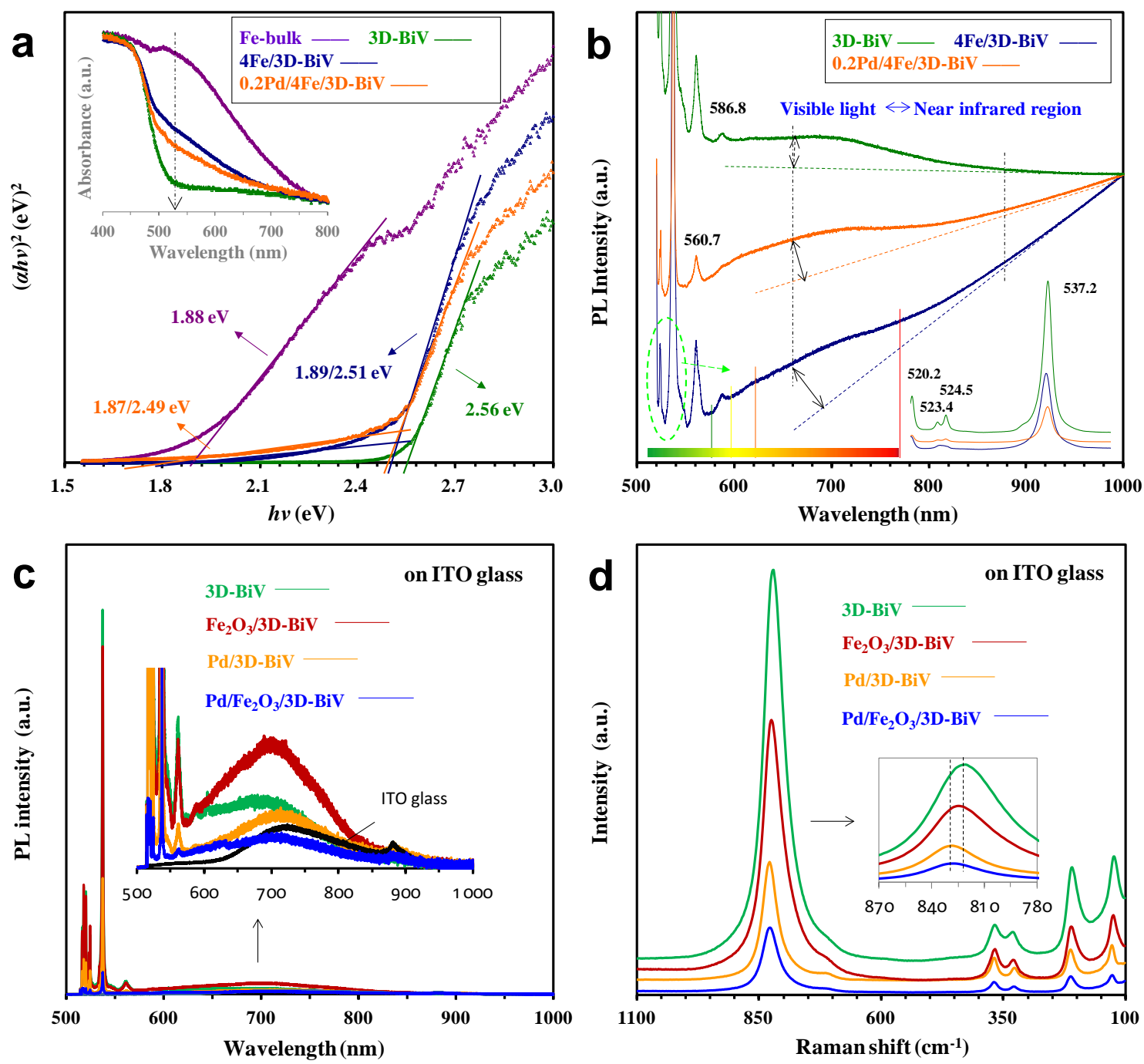

Figure 4. Optical behaviors of (a) UV-Vis diffuse reflectance spectra (inset) together with plots of $(\alpha h v)^{2}$ versus $h v$ and (b) PL spectra of the powder samples $(0.2 \mathrm{Pd} / 4 \mathrm{Fe} / 3 \mathrm{D}-\mathrm{BiV}, 4 \mathrm{Fe} / 3 \mathrm{D}-\mathrm{BiV}$, 3D-BiV, and Fe-bulk), (c) PL spectra and (d) laser Raman of various photoelectrode samples $\left(\mathrm{Pd} / \mathrm{Fe}_{2} \mathrm{O}_{3} / 3 \mathrm{D}-\mathrm{BiV}, \mathrm{Pd} / 3 \mathrm{D}-\mathrm{BiV}, \mathrm{Fe}_{2} \mathrm{O}_{3} / 3 \mathrm{D}-\mathrm{BiV}\right.$, and 3D-BiV) on ITO glass. 

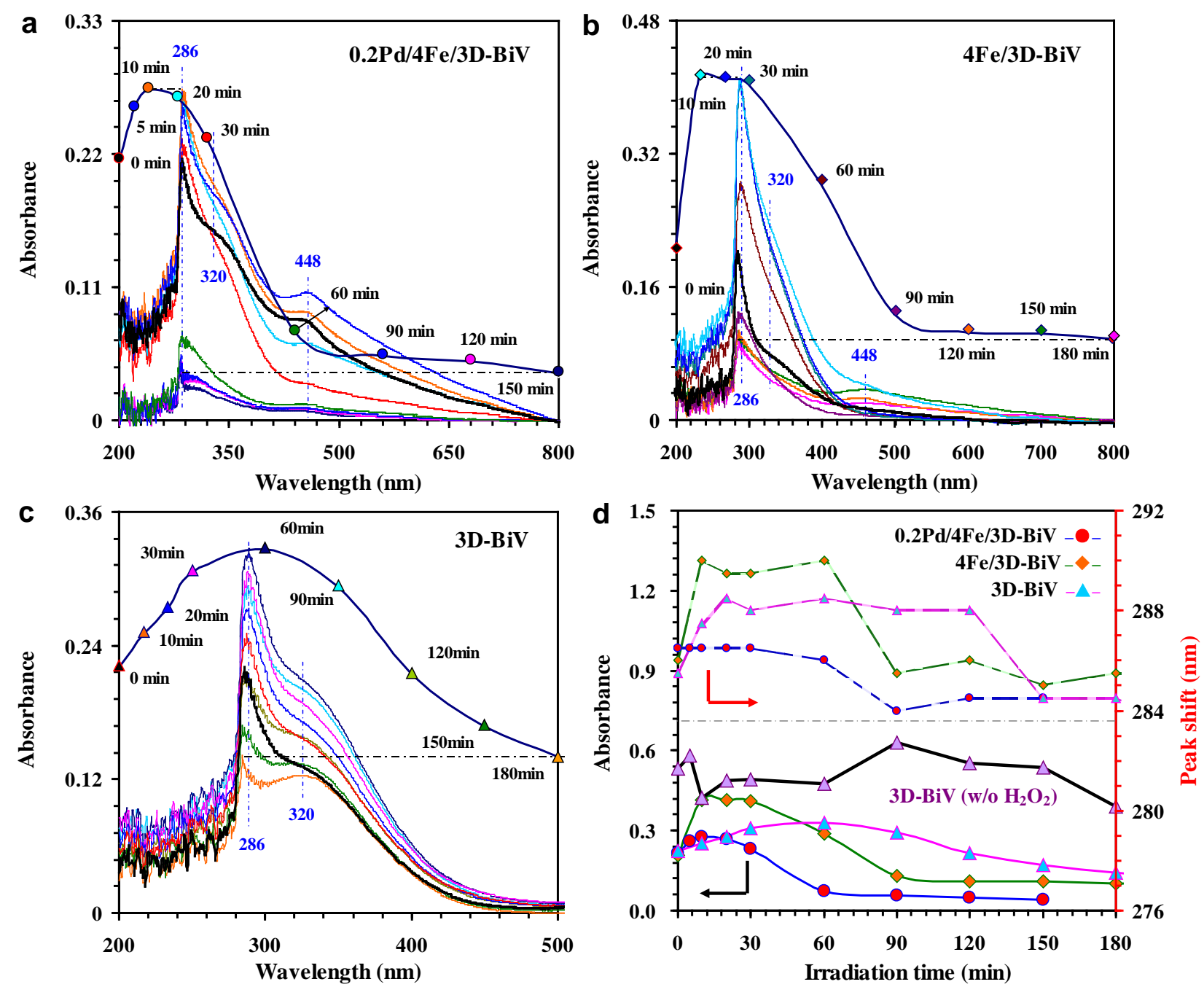

Figure 5. Photocatalytic performance of $0.2 \mathrm{Pd} / 4 \mathrm{Fe} / 3 \mathrm{D}-\mathrm{BiV}, 4 \mathrm{Fe} / 3 \mathrm{D}-\mathrm{BiV}$, and $3 \mathrm{D}-\mathrm{BiV}$ for phenol degradation under visible-light $(\lambda>400 \mathrm{~nm})$ irradiation, respectively. (a-c) Absorbance as well as maximal absorbance versus wavelength over the 3DOM-structured samples for the degradation of phenol $\left(C_{0}=0.4 \mathrm{mmol} / \mathrm{L}\right)$ aqueous solution at different reaction time, and $(\mathrm{d})$ maximal absorbance and its corresponding absorption wavelength versus irradiation time over the 3DOM-structured samples. 

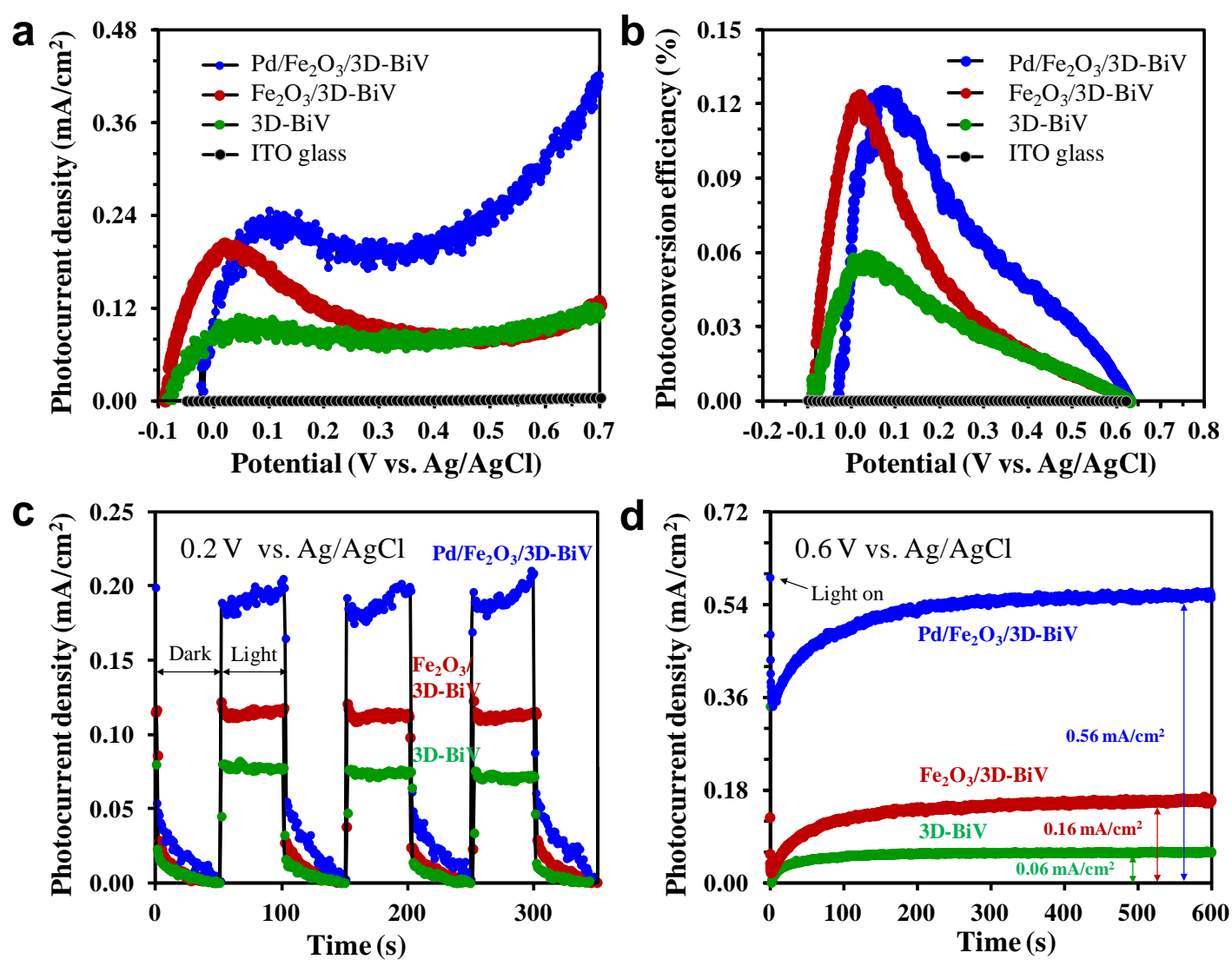

Figure 6. PEC water splitting performance of various photoelectrode samples in $0.01 \mathrm{~mol} / \mathrm{L}$ $\mathrm{Na}_{2} \mathrm{SO}_{4}$ electrolyte under light irradiation of (a) variation of photocurrent density versus applied voltage, (b) photoconversion efficiency as a function of applied potential, (c) transient photocurrent density versus time, and (d) transient photocurrent responses under visible light. 


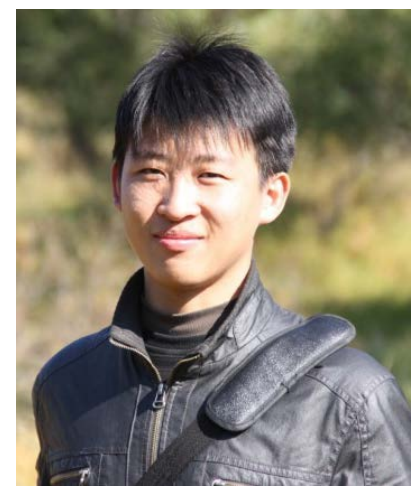

Kemeng Ji received his first PhD degree in Applied Chemistry from Beijing University of Technology, China, in 2014. Now he is a Ph.D. candidate in materials science in Tohoku University and also a fellow of Japan Society for the Promotion of Science (JSPS) from 2016 to 2018. His present research includes the development and characterization of nanoporous materials for environment and energy-related applications.

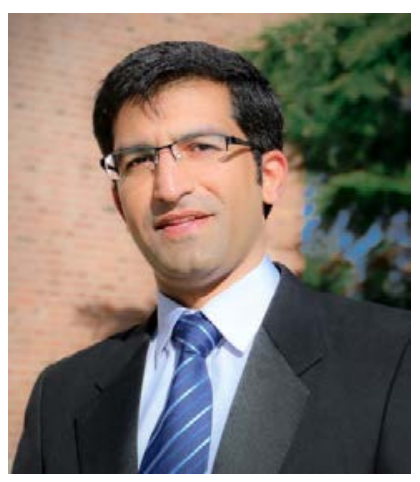

Hamidreza Arandiyan received his PhD in 2014 from the School of Environment at Tsinghua University, China. Afterwards, he worked in the laboratory of Prof. Hongxing Dai as part of the Catalysis Chemistry and Nanoscience group at Beijing University of Technology. He is now serving as a Vice-Chancellor's Research Fellow in the School of Chemical Engineering at University of New South Wales. His research interests are on new synthesis 3D ordered macroporous materials.

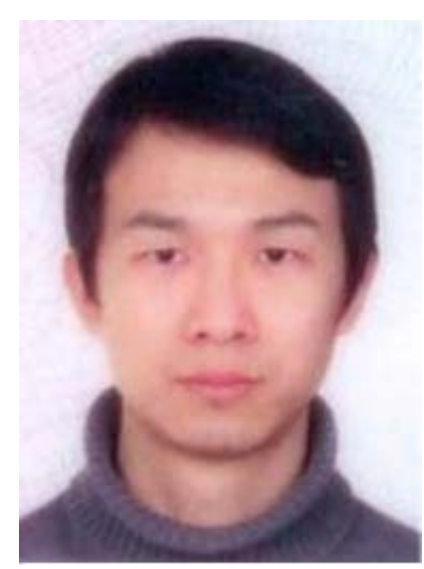

Pan Liu received his $\mathrm{PhD}$ degree in Institute of Microstructure and Properties of Advanced Materials from Beijing University of Technology in 2012. After that he worked as a postdoctoral fellow in Advanced Institute for Materials Research (AIMR), Tohoku University. His research interests include the application of advanced electron microscopy to materials science. Particular interest goes to nanostructured materials, nanoporous metals, battery materials, 2D materials and ceramics. 


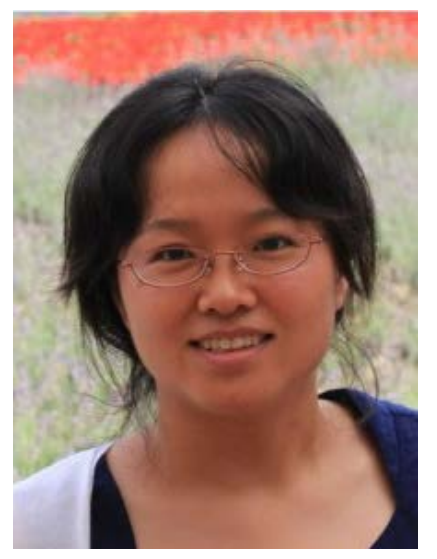

Ling Zhang received her PhD degree (2011) in Graduate School of Engineering from Tohoku University, Japan. She joined School of Optical-Electrical and Computer Engineering, University of Shanghai for Science and Technology in China as a Professor in 2013. Her current research interests include optical sensor, ultrasensitive detection and plasmonic materials fabrication.

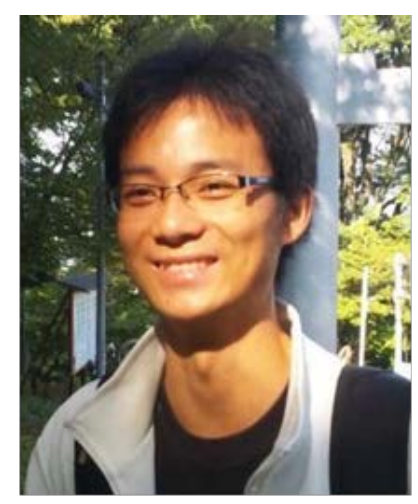

Jiuhui Han received his master degree in materials science from Tohoku University in 2014. Now he is a $\mathrm{PhD}$ candidate in Tohoku University and his current research focuses on the development and characterization of nanoporous materials for energy-related applications.

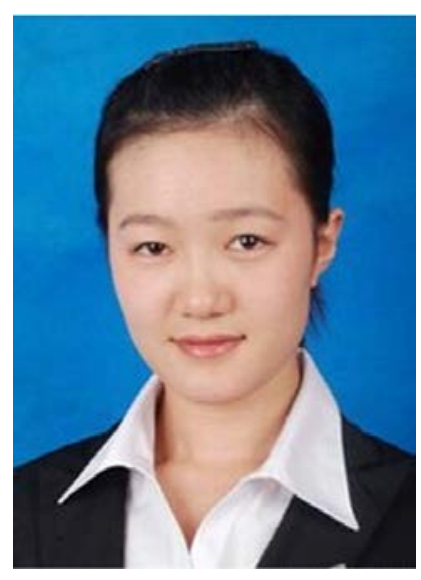

Yacong Xue received her bachelor degree (2013) in Biomedical Engineering from Yanshan University, China. She joined Tohoku University, Japan as a graduate student in 2014. Since 2015 she joined in Japan Thermal Spray Society (JTSS). Her current research is focus on the investigation of $\mathrm{TiO}_{2}$ film for dye sensitized solar cell prepared by low pressure cold spray technique. 


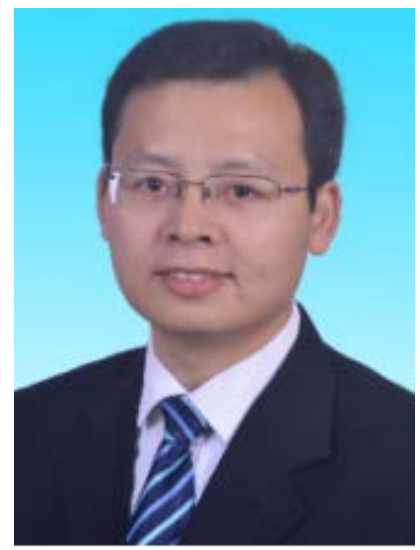

Jungang Hou received his $\mathrm{PhD}$ degree (2010) in materials science from Tianjin University, China. He joined the faculty of University of Science and Technology Beijing and was promoted to associate professor in 2013. He worked in Tohoku University as a fellow of Japan Society for the Promotion of Science (JSPS) from 2014 to 2015. In 2015, he joined the faculty of Dalian University of Technology as a professor. His current research interests include semiconductor photocatalysis, photocatalytic hydrogen production, $\mathrm{CO}_{2}$ reduction to hydrocarbon fuels and synthesis and applications of nanostructured materials.

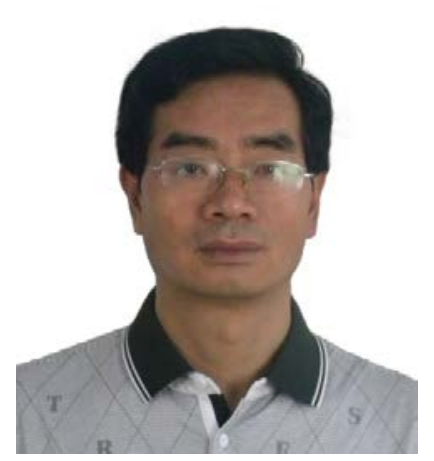

Hongxing Dai received his $\mathrm{PhD}$ degree (2001) in heterogeneous catalysis from Hong Kong Baptist University, Hong Kong, China. He did postdoctoral research in Lawrence Berkeley National Laboratory and University of California at Berkeley from 2002 to 2003. He joined the faculty of Beijing University of Technology as a full professor in 2003. His current research interests include catalytic combustion of organics, selective oxidation of light hydrocarbons, catalytic removal of automotive exhaust, synthesis of nanosized and porous materials, and photocatalytic degradation of organics. 